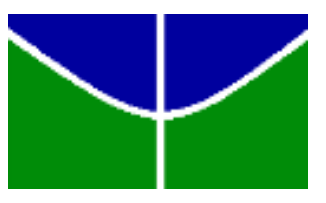

UNIVERSIDADE DE BRASÍLIA

FACULDADE DE AGRONOMIA E MEDICINA VETERINÁRIA

PROGRAMA DE PÓS-GRADUAÇÃO EM AGRONOMIA

EFEITO DO MOMENTO DE APLICAÇÃO DE FUNGICIDA E DA ÉPOCA DE SEMEADURA NO CONTROLE DA FERRUGEM ASIÁTICA DA SOJA

Lara Line Pereira de Souza

DISSERTAÇÃO DE MESTRADO EM AGRONOMIA

BRASÍLIA/DF

DEZEMBRO/2015 


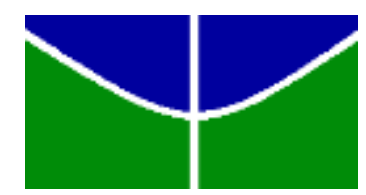

UNIVERSIDADE DE BRASÍLIA

FACULDADE DE AGRONOMIA E MEDICINA VETERINÁRIA PROGRAMA DE PÓS-GRADUAÇÃO EM AGRONOMIA

EFEITO DO MOMENTO DE APLICAÇÃO DE FUNGICIDA E DA ÉPOCA DE SEMEADURA NO CONTROLE DA FERRUGEM ASIÁTICA DA SOJA

LARA LINE PEREIRA DE SOUZA

ORIENTADOR: LUIZ EDUARDO BASSAY BLUM

DISSERTAÇÃO DE MESTRADO EM AGRONOMIA

PUBLICAÇÃO: 99/2015

BRASÍLIA/ DF

DEZEMBRO/2015 


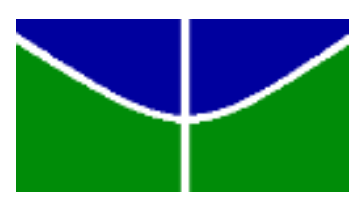

UNIVERSIDADE DE BRASÍLIA

FACULDADE DE AGRONOMIA E MEDICINA VETERINÁRIA

PROGRAMA DE PÓS-GRADUAÇÃO EM AGRONOMIA

\section{EFEITO DO MOMENTO DE APLICAÇÃO DE FUNGICIDA E DA ÉPOCA DE SEMEADURA NO CONTROLE DA FERRUGEM ASIÁTICA DA SOJA}

\section{LARA LINE PEREIRA DE SOUZA}

DISSERTAÇÃO DE MESTRADO SUBMETIDA AO PROGRAMA DE PÓSGRADUAÇÃO EM AGRONOMIA, COMO PARTE DOS REQUISITOS NECESSÁRIOS À OBTENÇÃO DO GRAU DE MESTRE EM AGRONOMIA. APROVADA POR:

LUIZ EDUARDO BASSAY BLUM - Professor Doutor (Universidade de Brasília); CPF: 333.965.071-34; E-mail: luizblum@unb.br - Orientador.

JOSÉ RICARDO PEIXOTO - Professor Doutor (Universidade de Brasília); CPF: 354356236-34; E-mail: peixoto@unb.br-Examinador interno ao PPG-AGRO.

ADALBERTO CORRÊA CAFÉ FILHO - Professor Doutor (Universidade de Brasília); CPF: 210332691-15; E-mail: cafefilh@unb.br - Examinador externo ao PPGAGRO.

BRASÍLIA/DF, 16 de dezembro de 2015. 


\section{FICHA CATALOGRÁFICA}

SOUZA, Lara Line Pereira de
EFEITO DO MOMENTO DE APLICAÇÃO DE FUNGICIDA E DA ÉPOCA
DE SEMEADURA NO CONTROLE DA FERRUGEM ASIÁTICA DA SOJA.
Orientação: Luiz Eduardo Bassay Blum - Brasília, 2015.
55 p.: il
Dissertação de Mestrado (M) - Universidade de Brasília / Faculdade de
Agronomia e Medicina Veterinária, 2015.
1. Soja 2. Ferrugem asiática da soja 3. Aplicação de fungicida 4. Época de
semeadura I. Blum, L.E.B. II. Dr ${ }^{\circ}$.
CCD ou CDU

\section{REFERÊNCIA BIBLIOGRÁFICA}

SOUZA, L.L.P. Efeito do momento de aplicação de fungicida e da época de semeadura no controle da ferrugem asiática da soja. Brasília: Faculdade de Agronomia e Medicina Veterinária, Universidade de Brasília, 2015, 55 páginas. Dissertação.

\section{CESSÃO DE DIREITOS}

Nome do Autor: LARA LINE PEREIRA DE SOUZA

Título da Dissertação de Mestrado: EFEITO DO MOMENTO DE APLICAÇÃO DE FUNGICIDA E DA ÉPOCA DE SEMEADURA NO CONTROLE DA FERRUGEM ASIÁTICA DA SOJA.

Grau: Mestre Ano: 2015.

É concedida à Universidade de Brasília de Brasília permissão para reproduzir cópias desta dissertação de mestrado para única e exclusivamente propósitos acadêmicos e científicos. O autor reserva para si os outros direitos autorais, de publicação. Nenhuma parte desta dissertação de mestrado pode ser reproduzida sem a autorização por escrito do autor. Citações são estimuladas, desde que citada à fonte.

LARA LINE PEREIRA DE SOUZA

CPF: 024.747.241-76

SGAN 912, MÓD. D, BLOCO F, APT 208, COND. PARK VILLE/ CEP: 70790-120

Brasília- DF, Brasil. Telefone: (61) 9691-7435/ e-mail: laralinepereira@gmail.com 
A meu querido pai, meu grande fã e incentivador e a quem tem toda a minha admiração e amor. Pelos rumos que Deus encaminha a vida, entendemos o significado da palavra perdão e amor. 


\section{AGRADECIMENTOS}

Agradeço a Deus pela vida e saúde.

Agradeço à minha família, minha base, meu tudo. Ao esforço de meus pais, Ana Maria e Wilson, que me proporcionou chegar onde estou e a quem sou eternamente grata pela educação que me ofereceram. A minha grande companheira, amiga e irmã Aline, pelo exemplo e pelos momentos de ajuda mútua que nos fizeram quem somos.

Agradeço a Universidade de Brasília pela oportunidade de reciclagem de conhecimentos e a possibilidade de enorme aprendizado na realização deste mestrado

Agradeço o Instituto Phytos que me proporcionou a realização do ensaio e me ofereceu um excelente suporte para realização das avaliações. Agradeço ao técnico de campo Iago pelo auxílio nas coletas em campo e pela disponibilidade de sempre ajudar. Agradeço o pesquisador do Instituto Phytos, Nédio Tormen e a mestranda Maíne Lerner pela oportunidade de realização do ensaio e pelo excelente auxílio técnico.

Agradeço meu orientador Luiz Eduardo Bassay Blum pelos ensinamentos e auxílio no desenvolvimento desta tese.

Agradeço a Secretaria de Estado de Agricultura, Abastecimento e Desenvolvimento Rural do Distrito Federal pela autorização de realização deste mestrado.

Agradeço o produtor rural que "madruga" todos os dias para fornecer a alimentos de qualidade em nossa mesa. Parabéns pela coragem e heroísmo de lutar contra tantas dificuldades. 


\section{SUMÁRIO}

INTRODUÇÃ

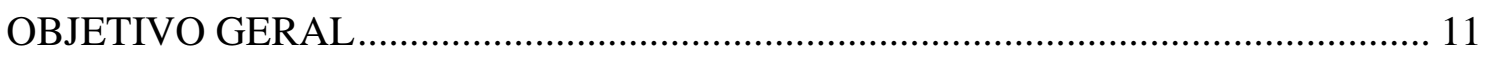

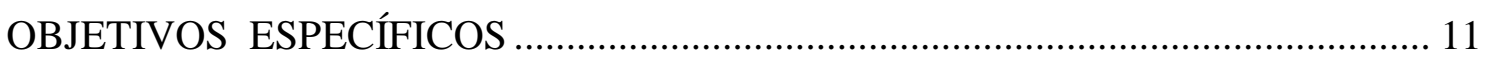

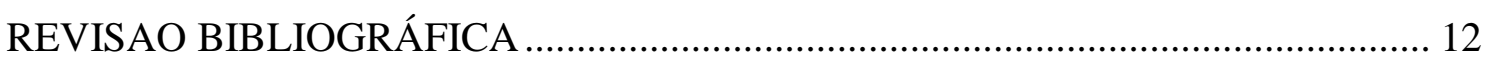

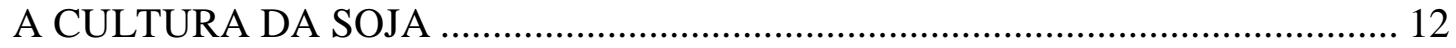

O CONTROLE DA FERRUGEM ASIÁTICA DA SOJA......................................... 13

MOMENTO DA APLICAÇÃO DE FUNGICIDA PARA CONTROLE DA

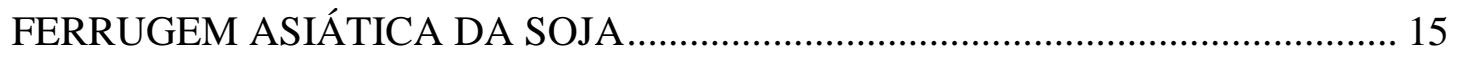

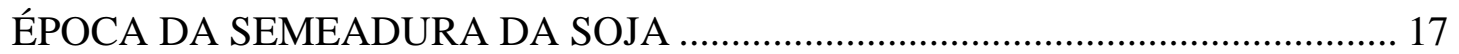

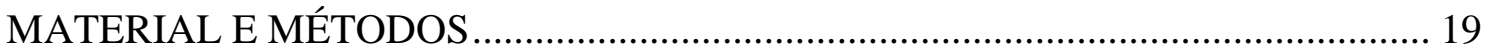

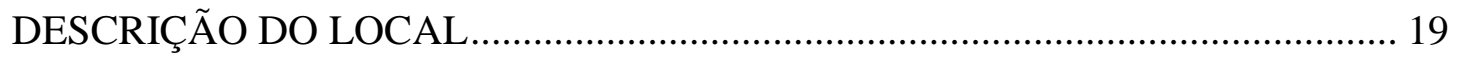

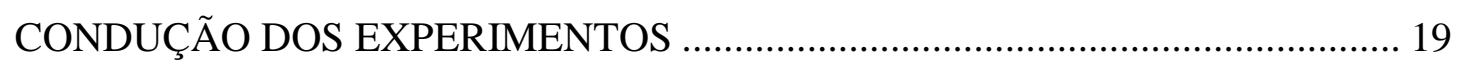

DELINEAMENTO EXPERIMENTAL E TRATAMENTOS …............................. 20

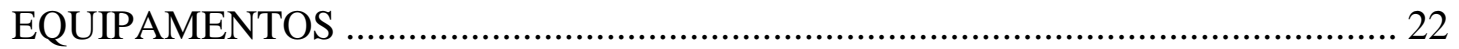

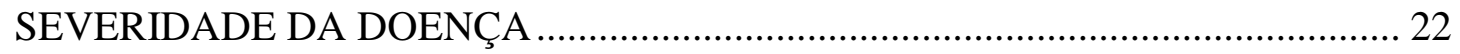

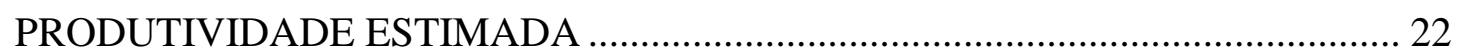

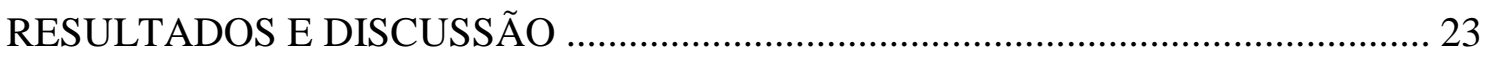

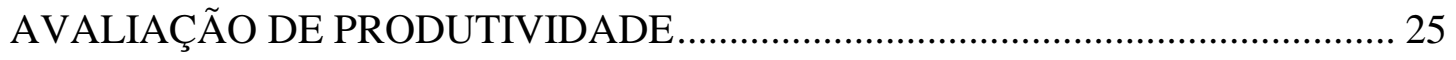

Avaliação de produtividade comparando as diferentes épocas de plantio ........................25

Avaliação de produtividade comparando os diferentes momentos de aplicação do fungicida......

AVALIAÇÃO DA ÁREA ABAIXO DA CURVA DE PROGRESSO DA DOENÇA (AACPD)

Avaliação de AACPD comparando as diferentes épocas de plantio. .29

Avaliação de AACPD comparando os diferentes momentos de aplicação do fungicida 30

CORRELAÇÃO DOS DADOS DE PRECIPITAÇÃO, SEVERIDADE (AACPD) E

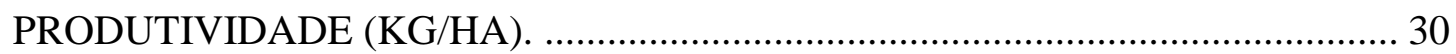

CORRELAÇÃO DOS RESULTADOS DE PRODUTIVIDADE E SEVERIDADE 36 CONCLUSÃO 37

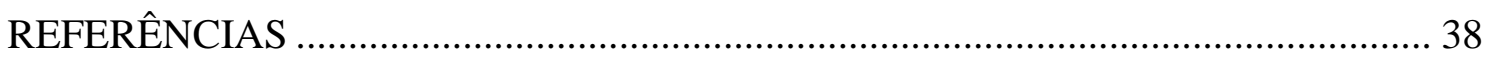

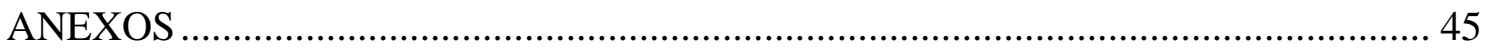




\section{RESUMO}

O Brasil é o maior produtor de soja (Glycine max) do mundo. Somente na safra 2014/2015, foram produzidas cerca de 97 milhões de toneladas de soja, dessas, cerca de 46,22 milhões de toneladas foram exportadas. A ferrugem asiática da soja (Phakopsora pachyrhizi) é considerada a principal doença da soja. Tal doença causa desfolha precoce, impedindo a completa formação dos grãos e drástica redução na produtividade. Devido à escassez de outras medidas, a aplicação de fungicida ainda é a principal forma de controle desta doença. Estudos mostram que a aplicação de fungicida de proteção é a principal forma de controle da ferrugem asiática. Um dos maiores desafios para o sojicultor brasileiro na atualidade é a decisão de quando aplicar o fungicida de proteção contra a ferrugem asiática. Os sojicultores do Distrito Federal (DF), em sua maioria, adotam a calendarização da aplicação de fungicida de proteção com uma média de 3 aplicações por safra em cultivares de ciclo médio a precoce. O objetivo deste trabalho foi o estudo de diferentes épocas de plantio e diferentes momentos de aplicação de fungicida de proteção para o controle da ferrugem asiática, propondo ao fim, um calendário de aplicação do fungicida de proteção e recomendação de época de plantio para a região do DF. O experimento foi conduzido no Instituto Phytos, localizado em Planaltina/DF, utilizando o delineamento experimental blocos ao acaso, onde cada bloco correspondeu a seis diferentes épocas de plantio, com cinco tratamentos que correspondiam aos diferentes momentos de aplicação de fungicida. Cada tratamento foi repetido quatro vezes em cada bloco. Os dados foram submetidos á análise de variância pelo teste de $\mathrm{F}$ e as diferenças entre as médias, quando significativas, foram comparadas pelo teste de Tukey. Foram realizadas análises de produtividade e severidade nas parcelas e coleção das variáveis com a precipitação. A semeadura precoce, logo no início das chuvas da safra, e aplicação de fungicida de proteção baseado nos estádios fenológicos da planta resultaram em uma menor severidade da doença e maior produtividade média. Plantios tardios e a não aplicação de fungicida ou aplicações com atraso resultaram no aumento da severidade da doença e redução da produtividade.

Palavras-chave: Soja, Ferrugem asiática da soja, aplicação de fungicida, época de semeadura. 


\begin{abstract}
Brazil is the largest producer of soybeans (Glycine max) in the world. In 2014/2015 only, approximately of 46.22 million tons of soybeans were exported. Asian Soybean Rust (Phakopsora pachyrhizi) is considered the main disease of soybean. This disease causes early defoliation, preventing the complete formation of grains and drastic reduction in productivity. Due to the limitation of other measures, the application of fungicide is still the main way to control this disease. Studies show that protective fungicide application is the main form of Asian rust control. One of the biggest challenges for the Brazilian soybean sector today is to optimize the decision about when to apply fungicide for protection against rust. Most soybean growers of the Federal District adopt the calendar schedule for fungicide application with an average of 3 applications per crop in mid to early cycle cultivars. The aim of this work was to study different planting seasons and different times of application of fungicides for the control of Asian rust, proposing to end, a timetable for the implementation of protective fungicide and recommendation of planting season for the region of the Federal District. Early seeding and protective fungicide application based on phenological stages of the plant resulted in lower disease severities and higher average productivity. Late plantings and the non-application of fungicide or delayed applications resulted in an increased in the severity of the disease and grain yield reduction
\end{abstract}

Keywords: soybean, Asian Soybean Rust, fungicide application, seeding. 


\section{INTRODUÇÃO}

Segundo dados da CONAB, 2014, o Brasil é o maior produtor de soja (Glycine max) do mundo. O Brasil atingiu na safra 2014/2015 o recorde de 96,24 milhões de toneladas colhidas (CONAB, 2015), sendo a cultura agrícola brasileira que mais cresceu nas últimas três décadas, correspondendo a $49 \%$ da área plantada em grãos do país (MAPA, 2015). No Brasil, mais de 40 doenças têm limitado a produtividade e rentabilidade desta cultura.

A ferrugem asiática da soja ainda é considerada uma das doenças mais severas que atingem a sojicultura brasileira. A doença é causada pelo fungo Phakopsora pachyrhizi. Tal fungo é disseminado pelo vento a longas distancias, motivo pelo qual a doença se espalhou rapidamente por todas as regiões produtoras do país. A doença causa desfolha precoce das plantas, impedindo assim a completa formação dos grãos, com consequente redução da produtividade. Os danos variam de 10 a 90\% ((SINCLAIR; HARTMAN, 1999; YORINORI et al., 2002), dependendo das condições ambientais e do estádio fenológico em que se encontra a cultura no momento da infecção. O aumento do número de aplicações de fungicidas nas lavouras também é um prejuízo, uma vez que eleva o custo de produção. Segundo dados do Consórcio Antiferrugem, o custo ferrugem (somatório do custo de aquisição do fungicida, da aplicação do produto e perdas em grãos e arrecadação) na safra 2014/15 foi de 2,2 bilhões de dólares.

Devido à escassez de outras medidas, a aplicação de fungicidas é a principal forma de controle da ferrugem asiática da soja. O controle químico preventivo e a calendarização de aplicação tem sido prática amplamente adotada no campo. Porém, aplicações precoces, tardias ou frequentes podem se fazer necessárias ou ineficazes para maximizar os rendimentos. A aplicação de fungicidas com base no princípio da proteção apresenta um controle de ferrugem superior à aplicação de fungicidas baseados no princípio curativo ou de erradicação. Contudo, um controle muito precoce pode acarretar um número de aplicação maior que o necessário, elevando o custo de produção e provocando um aumento da resistência do patógeno.

Avaliar o momento correto da aplicação do fungicida para controle da ferrugem tem-se mostrado um dos grandes desafios da sojicultura. Através de um correto posicionamento de quando aplicar o fungicida seria possível reduzir os danos que a 
doença provoca na planta, reduzindo os custos de produção e maximizando os rendimentos. 


\section{OBJETIVO GERAL}

Avaliar o momento correto para aplicação de fungicidas para controle da ferrugem asiática da soja (FAS) e comparar a aplicação de fungicidas baseada em dias após a emergência (DAE) com a aplicação baseada no estádio fenológico da planta.

\section{OBJETIVOS ESPECÍFICOS}

1. Avaliar o momento correto para aplicação de fungicida para controle da ferrugem asiática da soja (FAS).

2. Avaliar a severidade da FAS em diferentes tratamentos de aplicação de fungicida protetor.

3. Avaliar a severidade da FAS em diferentes épocas de plantio em áreas com incidência do patógeno da ferrugem asiática da soja.

4. Avaliar o rendimento (em $\mathrm{kg} / \mathrm{ha}$ ) da cultura da soja em diferentes tratamentos de aplicação de fungicida protetor.

5. Avaliar o rendimento (em $\mathrm{kg} / \mathrm{ha}$ ) da cultura da soja em diferentes épocas de plantio em áreas com incidência do patógeno da ferrugem asiática da soja. 


\section{REVISÃO BIBLIOGRÁFICA}

\section{A CULTURA DA SOJA}

O Brasil é maior produtor de soja do mundo (CONAB, 2014). A produção na safra 2014/2015, atingiu a quantidade recorde de 96,24 milhões de toneladas colhidas, representando um incremento de $11,5 \%$ em relação ao produzido na safra anterior (CONAB, 2015).As exportações totais de soja para safra 2014/15 foram estimadas em aproximadamente 46,22 milhões de toneladas. Segundo a Secretaria de Comercio Exterior (SECEX), de janeiro a abril de 2015 o Brasil exportou, aproximadamente, 13,1 milhões de toneladas de soja, valor 4,2 milhões de toneladas a menos que no mesmo período do ano anterior. Em maio as exportações brasileiras chegaram a 9,34 milhões de toneladas, o maior valor histórico de exportação mensal, somando, assim, 22,44 milhões em exportações no período de janeiro a maio de 2015 (CONAB, 2015).

A soja é afetada por mais de 100 patógenos (SINCLAIR; HARTMAN, 1999). No Brasil, mais de 40 doenças causadas por fungos, bactérias, nematóides e vírus, têm limitado a produtividade e causado prejuízos financeiros pela necessidade do seu controle (PICININI; FERNANDES, 1995; YORINORI et al., 2005).

Conforme descrito por YORINORI, et al. (2004) a cultura da soja é atacada por duas espécies de fungo pertencente ao gênero Phakopsora: P. meibomiae (Arth.) Arth. (fase anamorfica Malupa vignae) e P. pachyrhizi Sydow \& P. Sydow (fase anamorfica Malupa sojae). Os autores descrevem que a diferenciação entre as duas espécies faz-se através da análise do DNA e através da morfologia dos teliosporos e das télias.

A ferrugem americana, causada por Phakopsora meibomiae ocorre naturalmente no continente americano (YORINORI, et al., 2004) e foi relatada pela primeira vez no Brasil em 1979 no estado de Minas Gerais (DESLANDES, 1979). O fungo possui uma ampla gama de hospedeiros, podendo infectar naturalmente 42 espécies em 19 gêneros de leguminosas e mais 18 espécies em 12 gêneros, quando inoculadas artificialmente (YORINORI, et al. 2004) . Ainda segundo YORINORI, et al. (2004), a ferrugem americana raramente causa perdas e a única epidemia foi registrada na safra 1987/88 em São Gotardo, MG.

A ferrugem asiática da soja, causada pelo fungo Phakopsora pachyrhizi Syd. \& P. Syd, é uma das principais doenças da cultura da soja nos país. Conforme descrito por CALDWELL \& LAING (2005), o inoculo do patógeno chegou ao continente africano 
transportado por correntes aéreas. Foi descrita pela primeira vez no continente sulamericano por MOREL (2011) no Paraguai e introduzida no Brasil no ano de 2001 no estado do Paraná. Conforme relatado por NAVARINI, et al. (2007) os sintomas são particularmente evidentes nas folhas, evoluindo desde urédias isoladas à áreas com pronunciada coalescência quando provoca amarelecimento e prematura abscisão foliar. São agrupados em lesões de coloração bronzeada com duas a cinco urédias e esporulação abundante ou formando lesões pardo-avermelhadas, com zero a duas urédias e esporulação esparsa. De acordo com YORINORI et al. (2004) desde a constatação de epidemias no país, a doença mostrou-se altamente agressiva e expandiuse rapidamente, provocando reduções de até $80 \%$ na produtividade.

\section{O CONTROLE DA FERRUGEM ASIÁTICA DA SOJA}

WHETZEL et al. 1925 e WHETZEL 1929 definiram que os princípios gerais de controle consistem da exclusão, erradicação, proteção, imunização e terapia. A exclusão visa a prevenção da entrada e estabelecimento de um patógeno em área ainda indene. A erradicação visa a eliminação de um patógeno de uma determinada área ou região. A proteção visa a prevenção do contato do patógeno com o hospedeiro. A imunização baseia-se no desenvolvimento de plantas resistentes visando o seu cultivo em área infestada com o patógeno. A terapia visa restabelecer a sanidade de uma planta com a qual o patógeno já estabelecera uma íntima relação parasítica.

A ferrugem asiática encontra-se dispersa por todas as regiões produtoras de soja do país, não cabendo para o caso em estudo, a aplicação do princípio da exclusão. Conforme já constatado por GODOY \& CANTERI (2004), a aplicação de fungicida para controle de ferrugem asiática não possui efeito erradicante, pois a grande quantidade de inóculo do patógeno torna a erradicação quase que inatingível. O princípio da resistência não se aplica para a ferrugem asiática da soja. A obtenção de cultivar de soja resistente à ferrugem asiática tem sido um desafio para pesquisa, pois a estabilidade dessa resistência é duvidosa, devido à grande variabilidade do patógeno (OLIVEIRA et al., 2005). Estudos realizados pela Embrapa Soja identificaram 11 cultivares com resistência à ferrugem (YORINORI et al., 2002), sendo essa resistência quebrada rapidamente com isolado do fungo proveniente do Mato Grosso. Cabendo assim, somente a aplicação dos princípios da terapia e proteção. GODOY \& CANTERI (2004) observaram que dentre um grupo de fungicidas com exceção do carbendazin, a 
aplicação de fungicidas para controle da ferrugem apresentou efeito protetor com controle acima de $90 \%$.

Para SOARES et al. (2004) e YORINORI et al. (2004) a aplicação de fungicidas é o principal método de controle da ferrugem asiática da soja, todavia, condições de clima aliados a grande quantidade de inóculo inicial do fungo em algumas regiões do país têm exigido um número elevado de pulverizações para controle da doença, aumentando assim, os custos de produção. Segundo TSCHANZ (1984) e DEL PONTE et al. (2006), a precipitação é o fator mais importante no progresso da ferrugem nas condições de campo. O molhamento foliar contínuo, seja pelo orvalho, seja pela chuva, sob condições ótimas de temperatura $\left(18^{\circ} \mathrm{C}\right.$ a $\left.26,5^{\circ} \mathrm{C}\right)$ favorece o rápido desenvolvimento da doença (MELCHING et al., 1989; ALVES et al., 2006).

No controle químico de pragas, doenças e plantas daninhas, dá-se muita importância ao produto e pouca atenção a técnica de aplicação. A consequência é a perda de eficácia, quando não o fracasso total do tratamento, com superdosagens e subdosagens que levam a perda de rentabilidade dos cultivos e danos ao ambiente (PRADO, et al., 2010).

Para RUPE \& SCONYERS (2008), os fungicidas apresentam melhor controle quando aplicados previamente à instalação da doença no campo ou quando esta se encontra em baixíssimos níveis, sobretudo se tratando de grandes áreas de cultivo. GODOY \& CANTERI (2004) também defendem que aplicação de fungicida baseado no princípio da proteção apresenta um controle de ferrugem asiática muito superior a aplicação de fungicidas baseados nos princípios da erradicação e terapia. Para CALAÇA (2007), a decisão do momento correto de aplicação de fungicida é fundamental para um eficiente controle da ferrugem. Atrasos no controle podem tornálo ineficaz. Em situações em que o inicio da doença ocorre próximo à fase reprodutiva, o rendimento cai pela metade do esperado e a severidade aumenta $0,25 \%$ ponto percentual por cada dia de atraso no controle.

Para o controle da FA são recomendados os fungicidas dos grupos químicos dos triazóis (tebuconazol, ciproconazol, propiconazol, miclobutanil), das estrobilurinas (azoxistrobina, piraclostrobina, trifloxistrobina, picoxistrobina) e das carboxamidas (oxicarboxim, fluxapyroxad), BUTZEN et al. (2005). Para BUTZEN et al. (2005) o êxito no controle químico, depende de fatores como: quando é realizada a aplicação do fungicida; uso de produtos com longo período residual; produtos de boa cobertura do 
alvo e ausência de atrasos na aplicação do fungicida . Este último, conforme descrito por PINTO et al. (2012) é fator determinante para sucesso do controle químico pois a doença possui alta taxa de progresso, fazendo do momento de aplicação o fator decisivo para a eficiência deste método de controle.

Devido a menor eficiência observada com os fungicidas do grupo dos triazóis, a partir da safra 2007/08, na região Centro Oeste, e nas demais regiões a partir da safra 2008/09, a Comissão de Fitopatologia da Reunião de Pesquisa da Região Central do Brasil, passou a indicar somente a utilização de misturas comerciais de triazóis com estrobilurinas para o controle da ferrugem, GODOY et al. (2010).Conforme constatado por EBONE et al. (2012) e GODOY et al. (2010), o tratamento com os fungicidas Trifloxistrobina + Proticonazol apresentou os melhores percentuais de controle da FA, protegendo o potencial produtivo da cultura e proporcionando um reflexo positivo no rendimento de grãos. Para PEREIRA, et al. (2012), tratamentos utilizando Protioconazol + Trifloxistrobina e posteriormente Ciproconazol + Trifloxistrobina apresentaram maior rendimento de grãos por hectare que demais tratamentos utilizando triazóis e estrobilurinas.

\section{MOMENTO DA APLICAÇÃO DE FUNGICIDA PARA CONTROLE DA FERRUGEM ASIÁTICA DA SOJA}

Aplicações precoces, tardias ou frequentes podem não ser eficazes ou necessárias para maximizar os rendimentos. A primeira aplicação é um dos fatores mais críticos para o sucesso do controle de doenças. Atrasos significativos na aplicação, após o estabelecimento da doença em níveis elevados, podem resultar em perdas significativas de produtividade (LEVY, 2005; MILES et al., 2004). Para GODOY et al. (2009) o monitoramento da doença é fundamental na tomada de decisão para o início das aplicações e o monitoramento da lavoura e do ambiente é fundamental para definição do intervalo entre aplicações.

Para GODOY et al. (2009) e NAVARRO et al. (2004), aplicações realizadas com níveis elevados de severidade não apresentam retorno em produtividade, apresentando produtividade semelhantes à testemunha sem controle. GODOY et al. (2009), constatou que é possível controle da FAS mesmo após introdução da doença, porém em baixos níveis de severidade quando em experimento conduzido em Londrina/PR concluíram 
que o controle da FAS realizado mesmo após o estabelecimento da doença (em níveis de até $2 \%$ de severidade) resultou em produtividades elevadas.

As diferenças regionais no Brasil não permitem a adoção de um modelo único nacional para o manejo da doença (GODOY et al., 2009). O planejamento de uso de fungicidas deve levar em consideração as regionalidades e os fatores de risco monitorados ao longo da safra. Porém, as razões para os produtores no Brasil, e de outros lugares do mundo, adotarem programas de aplicações calendarizadas têm base na dificuldade de identificar a doença no seu início e o potencial de dano sob situações de falha no manejo (GODOY et al., 2009).

O uso de fungicidas, ferramentas de aplicação e calendários de aplicações são aspectos importantes no manejo da ferrugem asiática da soja. Aplicações demasiadamente cedo, tarde ou frequentes podem não ser eficazes ou necessárias para maximizar os rendimentos (MUELLER, et al., 2009). Por isso, o monitoramento em campo é fundamental para efetivo controle da doença. Pensando nisso, MUELLER, et al. (2009), desenvolveram ensaio no Paraguai, Zimbábue e Estados Unidos e observaram que na maioria dos locais em estudo, a aplicação em R3 era considerada um tratamento eficaz para controle da ferrugem da soja. No entanto, o estudo observou que múltiplas aplicações (como três aplicações em R1, R3 E R5) resultaram em baixa área abaixo da curva de progresso da doença (AACPD) e alta produtividade. Porém, foi por vezes observado no estudo, que aplicações únicas próximas ao aparecimento de ferrugem apresentaram os mesmos resultados que parcelas que receberam um maior número de aplicações. Este resultado foi observado principalmente em Capitán Meza e Pirapó no Paraguai, onde a primeira pústula foi constatada dias após a primeira aplicação de fungicida, resultando em mesmos resultados de AACPD, desfolha e produtividade em tratamentos com aplicação única em R1 e tratamentos com três aplicações. Observaram também que aplicações feitas antes da constatação da primeira pústula tendem a resultar em maiores produtividades do que os observados em aplicações posteriores à primeira detecção de pústula. Além disso, constatou que parcelas onde havia baixas taxas de severidade não apresentaram influência significativa na produtividade da soja.

Para GODOY et al. (2009), aplicações sequenciais com base na fenologia da planta (R2 e R5.1) apresentam redução na severidade da ferrugem asiática e maior produtividade da planta. Já para REIS et al. (2007) o controle de ferrugem baseado no 
estádio fenológico da cultura pode não ser eficiente visto que o patógeno pode se instalar em qualquer estágio fenológico. LEVY (2005) conduziu experimento em Zimbábue, nos anos de 1998 a 2003 e constatou que três ou mais aplicações preventivas para ferrugem apresentaram maior eficiência e potencial produtivo em comparação a áreas que receberam uma ou duas aplicações nas fases do enchimento de grãos, o que foi insuficiente para o controle da doença. Ainda segundo LEVY (2005) o período crítico para proteção da cultura vai do estádio de florescimento (R1) até a maturação fisiológica (R7).

De acordo com GIORDANI (2007) a determinação do estádio de desenvolvimento que permite a melhor expressão fisiológica de cada cultivar é relevante no manejo das doenças foliares da soja. A ausência de correspondência entre a reação de cada cultivar às doenças foliares e a resposta ao controle químico, tem sido observada na cultura da soja, e indica que as cultivares podem variar não somente devido à ação dos fungicidas, mas principalmente devido à capacidade fisiológica de resposta ao controle químico própria de cada cultivar (NAVARINI, et al., 2007). NAVARINI, et al. (2007) constatou que o correto posicionamento do controle químico em relação a cada cultivar associado ao estádio de aplicação possui melhor resposta que a escolha de determinado ingrediente ativo, principalmente no caso de uma doença como a ferrugem, cuja taxa de progressão é elevada. Constatou também que a associação de ingredientes ativos, na medida em que o estádio de aplicação for corretamente posicionado, torna vital para um controle eficaz da doença.

\section{ÉPOCA DA SEMEADURA DA SOJA}

A época de semeadura influencia modificações fonológicas e morfológicas na planta, inclusive nos componentes da produção, como número de vagens e grãos (GARCIA, 1979; MARTINS $t$ al., 1999; PEIXOTO et al., 2000). Ensaio conduzido por DAROISH et al. (2005), observaram que plantas semeadas com mais antecedência, adquiriram mais tardiamente um índice de área foliar suficiente para a melhor interceptação de luz, devido a temperaturas baixas. Além disso, conforme descrito por PENDLETON \& HARTWIG (1973) o atraso na semeadura pode causar um aumento no grau de acamamento.

FARIA (2000) e KOMORI et al. (2004), constataram que semeaduras tardias causam uma redução na produtividade, principalmente quando semeadas cultivares 
precoces. As semeaduras ocorridas tardiamente causam uma redução do ciclo da soja visto a redução na duração do período reprodutivo (GARCIA, 1979; MARTINS et al., 1999; MARCHIORI et al., 1999; PEIXOTO et al., 2000), além de acarretar na redução do porte das plantas (KOMORI et al., 2004). A redução do período reprodutivo pode ser proporcional ao atraso da semeadura, principalmente em semeadura extremamente tardia (OLIVEIRA, 2010). Além disso, a semeadura tardia de cultivares precoces promovem uma redução de nós (GARCIA, 1979; MARTINS et al., 1999) e redução do número total de vagens e grãos por planta (PEIXOTO et al., 2000).

Em quase sua totalidade, o Brasil apresenta uma semeadura adequada entre meados de outubro e meados de dezembro, mas há que se considerar as restrições impostas pelo local e cultivar. (OLIVEIRA, 2010).

De acordo com DAROISH et al. (2005) a época de semeadura e a densidade de plantas têm efeitos significativos na obtenção de grãos e na produção biológica das plantas, isto porque estes fatores afetam o índice de área foliar em R5 e a taxa de assimilação líquida em todo o período de enchimento de grãos. DAROISH et al. (2005) constataram o índice de área foliar e a taxa de assimilação líquida decrescendo com o atraso na semeadura.

Dentre os fatores ambientais determinantes da competição por recursos, estão a densidade de plantas e a época de semeadura. A época de semeadura também está relacionada à luz, já que determina variação na taxa de radiação solar, durante o ciclo da planta (OLIVEIRA, 2010). 


\section{MATERIAL E MÉTODOS}

\section{DESCRIÇÃO DO LOCAL}

O experimento foi conduzido na safra agrícola, 2014/2015 na instalação experimental do Instituto Phytus, localizada no município de Planaltina, região do Distrito Federal em latitude $15^{\circ} 35^{\prime} \mathrm{S}$, longitude $47^{\circ} 42^{\prime} \mathrm{W}$ e altitude de 1175 metros.

O município de Planaltina-DF, inserido na região do cerrado brasileiro, apresenta clima, segundo a classificação de Köppen, AW Tropical estacional de savana megatérmico com temperatura média do mês mais frio acima de $18^{\circ} \mathrm{C}$. Tem precipitação média anual de $1.400 \mathrm{~mm}$ concentrada no período de outubro a março.

\section{CONDUÇÃO DOS EXPERIMENTOS}

A semeadura da soja foi realizada nos dias: 16/11/2014, 28/11/2014, 11/12/2014, 18/12/2014, 02/01/2015, 06/01/2015. Inicialmente pretendia-se utilizar um intervalo entre semeaduras de 10 dias. Porém fatores climáticos, outras demandas na área experimental e falta da semente no mercado após aplicação em 18/12/2014 impossibilitaram a manutenção do planejamento inicial. O experimento foi conduzido em região produtora de soja do Distrito Federal e a introdução da ferrugem asiática da soja em campo foi de forma natural, via dispersão pelo vento.

Foi utilizada a cultivar M 6952 IPRO (Intacta), da Monsoy® da marca comercial Monsanto® que se caracteriza por possuir grupo de maturação 6.9, hábito de crescimento indeterminado, resistência ao acamamento, resistência a doenças foliares, excelente desenvolvimento radicular e ser precoce. Foi adotado o espaçamento entre linhas de 0,5 m, com adubação de $200 \mathrm{~kg} \mathrm{ha}^{-1}$ de NPK 05-20-20. Foi adotada uma densidade de plantas de 10 plantas/m linear, resultando população final de 200.000 plantas.ha ${ }^{-1}$ Foi realizado o tratamento de sementes, utilizando: Imidacloprido (150 g.L ${ }^{-}$ $\left.{ }^{1}\right)+$ Tiodicarbe $\left(450 \mathrm{~g} . \mathrm{L}^{-1}\right)$ em $500 \mathrm{ml} .100 \mathrm{~kg}^{-1}$ de sementes, e Carbendazin $\left(500 \mathrm{~g} . \mathrm{L}^{-1}\right)$ na dose de $200 \mathrm{ml} 100 \mathrm{~kg}^{-1}$ de sementes e homogeneizadas utilizando um tambor rotativo com eixo excêntrico. Periodicamente foi realizado o manejo de plantas daninhas utilizando: Glifosato-Sal de Di-amônio (120g i.a ha $\left.{ }^{-1}\right)$. 


\section{DELINEAMENTO EXPERIMENTAL E TRATAMENTOS}

Para reduzir as interferências entre parcelas, foi semeado entre cada parcela, uma parcela testemunha. Assim, cada tratamento sofreu a mesma influência da maior fonte de inóculo presente na testemunha.

O delineamento experimental utilizado foi experimento em blocos ao acaso. Cada bloco correspondeu a uma época de plantio. Dentro de cada bloco os tratamentos foram aleatorizados (Tabela 1). Cada tratamento foi repetido quatro vezes. Cada repetição constitui uma parcela de cinco fileiras, com 5,0 m de comprimento e 2,5 $\mathrm{m}$ de largura, equivalente a uma área de $12,5 \mathrm{~m}^{2}$. Para reduzir ainda mais as interferências entre parcelas, a área útil adotada nas avaliações foi de apenas as três linhas principais, excluindo $50 \mathrm{~cm}$ de cada extremidade, formando assim, uma área útil de $6 \mathrm{~m}^{2}$.

Tabela 1. Descrição dos tratamentos experimentais através da discriminação do momento da aplicação dos fungicidas (*) em função do número de dias após a emergência das plântulas (DAE) e do estádio fenológico da soja.

\begin{tabular}{|c|c|}
\hline Momento & Aplicação do fungicida \\
\hline 1 & Testemunha, sem aplicação do fungicida \\
\hline 2 & Aplicação baseada em DAE** da planta \\
\hline 3 & Aplicação baseada no estádio fenológico da planta \\
\hline 4 & Aplicação baseada no tratamento 2 , somando sete dias de atraso \\
\hline 5 & Aplicação baseada no tratamento 3 , somando sete dias de atraso \\
\hline
\end{tabular}

Os dados foram submetidos à análise de variância pelo teste de $\mathrm{F}(\mathrm{P} \leq 5 \%)$ e as diferenças entre as médias, quando significativas, foram comparadas pelos testes de Tukey (P $\leq 5 \%$ ) usando o programa Assistat (SILVA \& AZEVEDO, 2009). Quando pertinente, uma análise de correlação e de regressão linear, foi efetuada entre as variáveis (severidade, produtividade e precipitação). Os quadros de ANOVA das variáveis avaliadas estão nos anexos (Tabelas 10 a 11).

Os tratamentos químicos utilizados em cada época de plantio foram (Tabela 1): (1) Testemunha, sem aplicação de fungicida, onde foi pulverizado apenas água; (2) Aplicação ‘calendarizada', sendo a primeira aplicação realizada entre 15 e 25 dias após a emergência (DAE) (Tabela 2); (3) Aplicação baseada nos estádios fenológicos da soja Fehr \& Caviness (1971) (Tabela 3); (4) Aplicação calendarizada (baseada em DAE) com sete dias de atraso em relação ao tratamento 2 (Tabela 2); (5) Aplicação baseada 
em estádio fenológico com sete dias de atraso em relação tratamento 3 (Tabela 3). Foram aplicados, de forma intercalada, os fungicidas: trifloxistrobina $\left(60 \mathrm{~g}\right.$ i.a ha $\left.{ }^{-1}\right)+$ protioconazol (70 g i.a ha $\left.{ }^{-1}\right)$ e trifloxistrobina $\left(60 \mathrm{~g}^{\mathrm{i} . \mathrm{a} \mathrm{ha}} \mathrm{h}^{-1}\right)+\operatorname{ciproconazol}\left(70 \mathrm{~g}\right.$ i.a ha ${ }^{-}$ ${ }^{1}$ ), utilizando o adjuvante a base de óleo metilado de soja a $0,25 \%$ v/v.

Tabela 2. Época de semeadura (EP), data da semeadura (DS), data da emergência das plântulas (DE) e momento da aplicação dos fungicidas (*) no momento $2(* *)$, baseado em DAE (Dias Após a Emergência).

\begin{tabular}{|c|c|c|c|c|c|}
\hline \multirow{2}{*}{ EP } & \multirow{2}{*}{ DS } & \multirow{2}{*}{ DE } & \multicolumn{3}{|c|}{$\mathbf{D A E}^{* * * *}$} \\
\hline & & & $1^{\circ}$ aplicação & $\mathbf{2}^{\circ}$ aplicação & $\mathbf{3}^{\circ}$ aplicação \\
\hline 1 & $16 / 11 / 2014$ & $24 / 11 / 2014$ & 25 & 45 & 15 dias após a $2^{\circ}$ aplicação \\
\hline 2 & $28 / 11 / 2014$ & $9 / 12 / 2014$ & 23 & 43 & 15 dias após a $2^{\circ}$ aplicação \\
\hline 3 & $11 / 12 / 2014$ & $16 / 12 / 2014$ & 21 & 41 & 15 dias após a $2^{\circ}$ aplicação \\
\hline 4 & $18 / 12 / 2014$ & $22 / 12 / 2014$ & 19 & 34 & 15 dias após a $2^{\circ}$ aplicação \\
\hline 5 & $2 / 1 / 2015$ & $6 / 1 / 2015$ & 17 & 32 & 15 dias após a $2^{\circ}$ aplicação \\
\hline 6 & $6 / 1 / 2015$ & $14 / 1 / 2015$ & 15 & 30 & 15 dias após a $2^{\circ}$ aplicação \\
\hline
\end{tabular}

*Trifloxistrobina $\left(60 \mathrm{~g}^{\mathrm{i} . \mathrm{a} \mathrm{ha}} \mathrm{ha}^{-1}\right)+$ protioconazol $\left(70 \mathrm{~g}\right.$ i.a ha $\left.{ }^{-1}\right)$ e trifloxistrobina $\left(60 \mathrm{~g}^{\mathrm{i}} . \mathrm{a} \mathrm{ha} \mathrm{ha}^{-1}\right)+$ ciproconazol (70 g i.a ha $\left.{ }^{-1}\right)$; ** $\mathrm{O}$ tratamento 4 consistiu da adição de 7 dias a cada aplicação apresentada; *** Dias após emergência; ****A aplicação do fungicida foi antecipada ao decorrer do tempo nas diferentes épocas de semeadura com a finalidade de realizar a aplicação do fungicida em momento cada vez mais precoce, aplicando assim o princípio da proteção da planta. Tal decisão foi tomada presumindo que a ferrugem asiática introduziria em todas as parcelas do ensaio em um único momento, evitando assim que houvesse diferença de pressão de inoculo do patógeno entre parcelas visto que a aplicação realizada na parcela plantada em 06/01/2015 poderia receber aplicação de fungicida em momento no qual a ferrugem asiática já estivesse introduzida no campo.

Tabela 3. Época de semeadura (EP), data da semeadura (DS) e momento da aplicação dos fungicidas (*) no 'tratamento 3' (**), baseado no estádio fenológico da soja.

\begin{tabular}{|c|c|c|c|c|}
\hline $\mathbf{E P}$ & $\overline{\text { DS }}$ & $\overline{1^{\circ} \text { aplicação }}$ & $2^{\circ}$ aplicação & $\mathbf{3}^{\circ}$ aplicação \\
\hline 1 & $16 / 11 / 2014$ & V6 & R1 & 15 dias após a $2^{\circ}$ aplicação \\
\hline 2 & 28/11/2014 & V6 & $\mathrm{R} 1$ & 15 dias após a $2^{\circ}$ aplicação \\
\hline 3 & $11 / 12 / 2014$ & V5 & R1 & 15 dias após a $2^{\circ}$ aplicação \\
\hline 4 & $18 / 12 / 2014$ & V5 & $\mathrm{R} 1$ & 15 dias após a $2^{\circ}$ aplicação \\
\hline 5 & $2 / 1 / 2015$ & V4 & Vn & 15 dias após a $2^{\circ}$ aplicação \\
\hline 6 & $6 / 1 / 2015$ & V4 & $\mathrm{Vn}$ & 15 dias após a $2^{\circ}$ aplicação \\
\hline
\end{tabular}

* Trifloxistrobina $\left(60 \mathrm{~g}^{\mathrm{i}} . \mathrm{a} \mathrm{ha} \mathrm{ha}^{-1}\right)+$ protioconazol $\left(70 \mathrm{~g}\right.$ i.a ha $\left.\mathrm{h}^{-1}\right)$ e trifloxistrobina $\left(60 \mathrm{~g} \mathrm{i.a} \mathrm{ha}^{-1}\right)+$ ciproconazol (70 g i.a ha $\left.{ }^{-1}\right)$; **O tratamento 5 consistiu da adição de 7 dias a cada aplicação apresentada; ***A aplicação do fungicida foi antecipada ao decorrer do tempo nas diferentes épocas de semeadura com a finalidade de realizar a aplicação do fungicida em momento cada vez mais precoce, aplicando assim o princípio da proteção da planta. Tal decisão foi tomada presumindo que a ferrugem asiática introduziria em todas as parcelas do ensaio em um único momento, evitando assim que houvesse diferença de pressão de inoculo do patógeno entre parcelas visto que a aplicação realizada na parcela plantada em 06/01/2015 poderia receber aplicação de fungicida em momento no qual a ferrugem asiática já estivesse introduzida no campo. 


\section{EQUIPAMENTOS}

Foi utilizado o pulverizador pressurizado (30 psi) por $\mathrm{CO}_{2}$, com quatro pontas de pulverização em leque duplo (TJ60 110. 02) a cada 0,50 m e aplicando um volume de calda de $150 \mathrm{~L} \mathrm{ha}^{-1}$. Próximo à área experimental, havia uma estação Meteorológica de Observação de Superfície Automática, que forneceu os dados referentes a variáveis climáticas que foram utilizados no experimento.

\section{SEVERIDADE DA DOENÇA}

Foram realizadas três avaliações por parcela, no intervalo de sete dias após a constatação da primeira pústula até a desfolha, baseadas na escala diagramática proposta por GODOY et al. (2006). Foram atribuídas notas percentuais (\%) individuais para cada folha avaliada. Foram avaliadas cinco folhas de cinco plantas por parcela. Com base nas avaliações de severidade da doença, foi calculada a área abaixo da curva de progresso da doença (AACPD), que permite uma avaliação mais estável e menos afetada pelo tempo de análise e variação ambiental (CAMPBEL; MADDEN, 1990), em que:

$$
\underset{\mathrm{i}=1}{\mathrm{n}-1} \mathrm{ACPD}=\sum\left(\mathrm{Y}_{\mathrm{i}+1}+\mathrm{Y}_{\mathrm{i}}\right) \mathrm{x}\left(\mathrm{T}_{\mathrm{i}+1}-\mathrm{T}_{\mathrm{i}}\right) / 2 \text {, onde }:
$$

$\mathbf{Y}_{\mathbf{i}}$ : severidade da doença na época da avaliação $\mathbf{i}(\mathbf{i}=1,2, \ldots, n) ; \mathbf{Y}_{\mathbf{i}+\mathbf{1}}$ : severidade da doença na época da avaliação $\mathbf{i}+\mathbf{1} ; \mathbf{T}_{\mathbf{i}}$ : época da avaliação $\mathrm{i}$, que geralmente considera $\mathbf{o}$ número de dias após emergência das plantas; $\mathbf{T}_{\mathbf{i}+\mathbf{1}}$ : época da avaliação i+1; $\mathbf{n}$ : Número total de observações.

A taxa de progresso da doença $(r)$ foi calculada com base no modelo logístico que descreve a epidemia: $\mathbf{r}=(\mathbf{1} / \mathbf{t}) \ln \left(\mathbf{X} / \mathbf{X}_{\mathbf{0}}\right)($ CAMPBELL \& MADDEN, 1990), onde: $\mathbf{r}=$ taxa aparente de progresso; $\mathbf{t}=$ tempo em dias decorrente entre a primeira e a última avaliação; $\mathbf{l n}=$ logaritmo natural; $\mathbf{X}=$ severidade da doença na última avaliação (\%); $\mathbf{X}_{\mathbf{o}}$ $=$ severidade da doença na primeira avaliação $(\%)$.

\section{PRODUTIVIDADE ESTIMADA}

Ao final do ciclo, as plantas foram colhidas, trilhadas e determinada a umidade através de medidor de umidade de grãos. As amostras foram pesadas em balança de precisão e a produtividade foi calculada corrigindo-se a umidade para um teor de $13 \%$. As épocas de semeadura 1, 2, 3, 4, 5 e 6, foram colhidas, respectivamente, nos dias: 28/3/2015, 4/4/2015, 11/4/2015, 18/4/2015, 25/4/2015 e 25/4/2015. 


\section{RESULTADOS E DISCUSSÃO}

A área experimental de instalação do ensaio é conhecida pela ocorrência tardia da ferrugem, isto porque tal área encontra-se localizada próxima a áreas de reserva ambiental da região. Historicamente, há epidemias de ferrugem asiática apenas nos meses de janeiro e fevereiro. Porém, a primeira pústula de ferrugem foi constatada no campo apenas no dia 4/3/2015 (Tabela 4).

Tabela 4. Estádio fenológico (EF) e data de constatação (DC) da primeira pústula em função das diferentes épocas (EP) e datas (DS) de semeadura da soja.

\begin{tabular}{cccc}
\hline EP & DS & EF & DC \\
\hline 1 & $16 / 11 / 2014$ & $\mathrm{R} 8.2$ & $4 / 3 / 2015$ \\
2 & $28 / 11 / 2014$ & $\mathrm{R} 6$ & $6 / 3 / 2015$ \\
3 & $11 / 12 / 2014$ & $\mathrm{R} 5.5$ & $7 / 3 / 2015$ \\
4 & $18 / 12 / 2014$ & $\mathrm{R} 5.4$ & $14 / 3 / 2015$ \\
5 & $02 / 01 / 2015$ & $\mathrm{R} 5.3$ & $14 / 3 / 2015$ \\
6 & $06 / 01 / 2015$ & $\mathrm{R} 5.2$ & $21 / 3 / 2015$ \\
\hline
\end{tabular}

Tabela 5. Média mensal (MM) e somatório do acumulado (SAC) de chuvas (mm) no mês, registrados pela estação meteorológica instalada na área do experimento.

\begin{tabular}{ccc}
\hline Mês/ano & MM $(\mathbf{m m})$ & SAC $(\mathbf{m m})$ \\
\hline Nov/14 & 11,1 & 334,2 \\
Dez/14 & 10,4 & 322,0 \\
Jan/15 & 2,5 & 78,2 \\
Fev/15 & 10,1 & 281,8 \\
Mar/15 & 6,4 & 198,4 \\
Abr/15 & 9,6 & 287,8 \\
Mai/15 & 1,6 & 50,2 \\
\hline
\end{tabular}

O maior volume de chuvas no mês de fevereiro propiciou um ambiente favorável ao desenvolvimento do fungo, possibilitando a avaliação da primeira pústula no início de março (Tabela 4). Já o elevado volume de chuvas constatado nos meses de março e abril de 2015, possibilitou ambiente propício ao aumento da severidade da doença. O molhamento foliar prolongado $(10 \mathrm{~h} / \mathrm{dia})$, temperatura noturna entre 18 e $24^{\circ} \mathrm{C}$, e chuvas frequentes mostraram-se como condições determinantes para o estabelecimento 
da doença (NAVARINI, et al., 2007). Conforme relatado por MADALOSSO, et al.(2010) chuvas frequentes entre os meses de fevereiro e março da safra 08/09, contribuíram para o aumento da severidade da ferrugem asiática iniciada após o estádio reprodutivo. Para DEL PONTE et al. (2006), a severidade da doença apresenta alta correlação positiva com a quantidade de chuvas.

Mas assim como observado por SOARES et al. (2004) a ocorrência tardia da doença gerou uma menor perda de produtividade comparada a outros ensaios onde a introdução da doença deu-se em fases mais precoces (fase vegetativa).

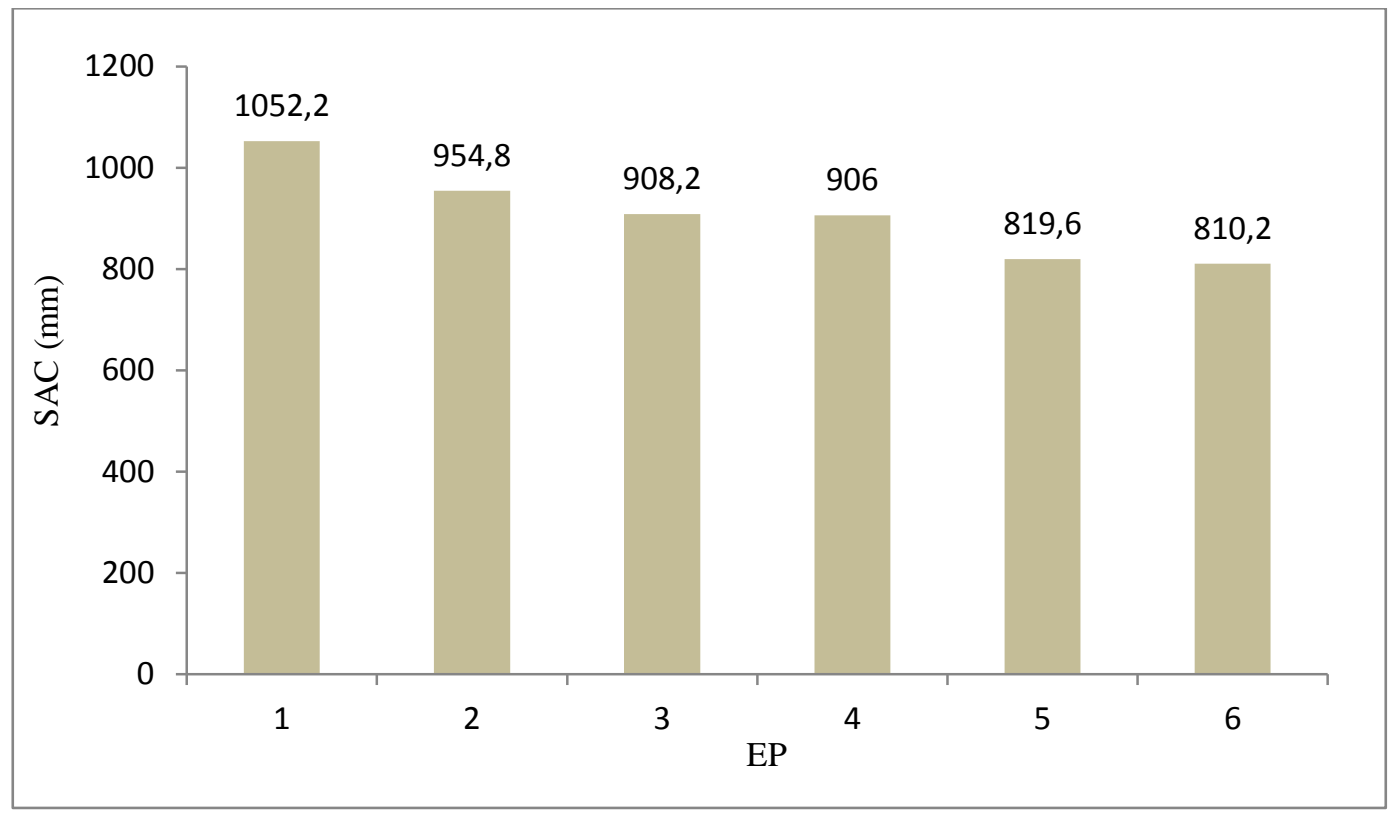

Figura 1. Somatório acumulado (SAC) de chuvas $(\mathrm{mm})$ por época de semeadura (EP), da data de plantio a colheita.

Em todas as épocas de semeadura do ensaio, a primeira pústula foi constatada apenas na fase reprodutiva (Tabela 4). Houve uma diferença de cerca de duas semanas entre a primeira constatação de ferrugem (semeadura em 16/11/2014) e a última constatação (semeadura em 6/1/2015). A semeadura em 16/11/2014 apresentou ferrugem no dia 4/3/2015, no estádio fenológico R8.2; a semeadura em 28/11/2014 apresentou ferrugem no dia 6/3/2015, em R6; a semeadura em 11/12/2014 apresentou ferrugem no dia 7/3/2015, em R5.5; a semeadura em 18/12/2014 apresentou ferrugem no dia 14/3/2015, em R5.4; a semeadura em 2/1/2015 também apresentou ferrugem no dia 14/3/2015, em R5.3; já a semeadura em 6/1/2015 apresentou ferrugem no dia 21/3/2015, em R5.2. 
A semeadura em 16/11/2014 apresentou a primeira pústula apenas em R8.2, quando já constatava-se mais de 50\% de desfolha à pré-colheita, o que inviabilizou a análise de severidade, área abaixo da curva de progresso da doença e taxa de progresso da doença da primeira época plantada (Tabela 4). Devido à ocorrência em estádio fenológico tão avançado (próximo a colheita), é possível que a ferrugem não tenha influenciado no desenvolvimento deste bloco, possuindo outros fatores bióticos e abióticos que tenham influenciado a redução da produtividade.

A primeira pústula foi constatada em estádio cada vez mais precoce da fase reprodutiva, iniciando em R8 na semeadura em 16/11/2015 e finalizando em R5.2 na semeadura realizada em 6/1/2015, o que gerará influências na produtividade.

\section{AVALIAÇÃO DE PRODUTIVIDADE}

\section{Avaliação de produtividade comparando as diferentes épocas de plantio}

A semeadura realizada em 28/11/2014 apresentou a maior produtividade média por hectare, $4785 \mathrm{~kg} / \mathrm{ha}$. A semeadura realizada em 16/11/2014 não diferenciou significativamente da semeadura realizada em 28/11/2014 e não diferenciou também das semeaduras realizadas em 11/12/2014, 18/12/2014 e 02/01/2015. As semeaduras realizadas em 11/12/2014, 18/12/2014 e 2/1/2015 não apresentaram diferença significativa entre si. Já a semeadura realizada em 6/1/2015 apresentou a menor produtividade média por hectare, dentre as épocas avaliadas (Tabela 6).

É possível observar que plantios tardios reduzem progressiva e drasticamente a produtividade da parcela. Assim como constatou NAVARINI, et al.(2007) a semeadura antecipada de cultivares de ciclo precoce são medidas de controle que propiciam redução na pressão de inóculo e contribuem para aumento na eficiência do controle químico, além de proporcionar maior produtividade por área.

A semeadura realizada em 06/01/2015 apresentou primeira pústula em estádio mais precoce em comparação às demais épocas de plantio, em R5.2 (Tabela 4). O estádio R5.2 caracteriza-se por ser a fase de inicio do enchimento do grão (de 10 a 25\%), demonstrando a influência da precocidade da introdução da ferrugem sobre a produtividade por hectare. Além disso, demonstrando que a introdução da ferrugem em 
um período crítico como o início do enchimento do grão influencia negativamente a produtividade média por hectare.

Tabela 6. Produtividade $(\mathrm{kg} / \mathrm{ha})$ de grãos de soja, área abaixo da curva de progresso da doença (AACPD) e taxa aparente de progresso da doença (r) nas diferentes épocas (EP) e datas (DS) de semeadura.

\begin{tabular}{cccc}
\hline EP & DS & Grãos $-\mathbf{k g} / \mathbf{h a}$ & AACPD** \\
\hline 1 & $16 / 11 / 2014$ & $4318,7 \mathrm{ab} *$ & - \\
2 & $28 / 11 / 2014$ & $4785,3 \mathrm{a}$ & $1150,3 \mathrm{c}$ \\
3 & $11 / 12 / 2014$ & $4122,9 \mathrm{~b}$ & $1284,6 \mathrm{bc}$ \\
4 & $18 / 12 / 2014$ & $3985,4 \mathrm{~b}$ & $1984,9 \mathrm{ab}$ \\
5 & $2 / 1 / 2015$ & $3915,1 \mathrm{~b}$ & $2692,7 \mathrm{a}$ \\
6 & $6 / 1 / 2015$ & $3113,5 \mathrm{c}$ & $1512,6 \mathrm{bc}$
\end{tabular}

*Médias da coluna seguidas por letras iguais não diferem entre pelo Teste de $(\mathrm{P} \leq 5 \%)$; ** Área Abaixo da Curva de Progresso da ferrugem em função da severidade da doença em \% de área foliar afetada.

É possível observar que uma diferença de apenas 4 dias entre a quinta época de plantio e a sexta época plantada (semeadura em 2/1/2015 e 6/1/2015), causam uma redução de $20 \%$ na produtividade, totalizando cerca de 13 sacas de soja $(60 \mathrm{~kg})$ a menos colhidas por hectare (Tabela 6.). Diferença maior é constatada quando se compara a segunda época plantada (em 28/11/2014) para a última época plantada (em 6/1/2015), ocorrendo uma redução de $34 \%$ na produtividade média, totalizando cerca de 27 sacas de soja $(60 \mathrm{~kg})$ a menos colhidas por hectare.

Plantios tardios expõem o hospedeiro a uma quantidade de inoculo do patógeno , resultando em maiores níveis de doença e redução da produtividade. Resultados semelhantes foram observados por NAVARINI et al. (2007), onde os dados obtidos demonstraram que a ferrugem da soja afetou significativamente o rendimento de grãos das cultivares de soja, com redução variável entre $10,0 \%$ e 40,4\%. Esta variação do rendimento observada por NAVARINI et al. (2007) foi influenciada pelo momento e pelo número de aplicações dos fungicidas.

A utilização de cultivares precoces, semeadas no início da época recomendada para cada região, tem sido uma das práticas de manejo recomendadas para evitar redução na produtividade devido a ferrugem (OLIVEIRA, GODOY \& MARTINS, 2005). SILVA et al. (2007)também observou que a ferrugem asiática foi mais severa nos blocos plantados em épocas mais tardias, apresentando grande e acelerada desfolha que 
resultou na redução drástica na produtividade. Indo ao encontro também dos resultados de YORINORI \& WILFRIDO (2002), que alertam que o controle da ferrugem asiática envolve várias estratégias de manejo, principalmente a semeadura de cultivares precoces nas épocas mais recomendadas para as regiões. Assim como observado por NAVARINI, et al. (2007) a destruição de hospedeiros secundários, semeadura antecipada de cultivares de ciclo precoce são medidas de controle que propiciam redução na pressão de inóculo e contribuem para aumento na eficiência do controle químico.

Não somente o fator ferrugem asiática da soja pode ter influenciado os resultados de produtividade estimada por diferentes épocas de plantio. Pois segundo já descrito por FARIA (2000) e KOMORI et al. (2004), a semeadura tardia de cultivares precoces causam uma redução na produtividade, isto porque há uma redução do ciclo da cultura, principalmente do ciclo reprodutivo, redução do porte de plantas, redução de vagens e grãos, redução do número de nós, dentre outros fatores.

Razões como um maior volume de chuvas ocorridas em todo ciclo vegetativo, fotoperíodo, menor incidência de outras doenças, dentre outros fatores pode ter causado a menor produtividade estimada no bloco semeado no dia 16/11/2014 comparativamente ao bloco semeado em 28/11/2014. De maneira geral, na cultura da soja, o período vegetativo e o porte das plantas são significativamente afetados por diferenças no fotoperíodo e na temperatura (CÂMARA, et al., 1997). Além disso, chuvas ocorridas, principalmente próximas ao enchimento dos grãos de soja são fatores determinantes no incremento de produtividade de uma área.

Assim, presume-se que as maiores produtividades constatadas nos blocos semeados antecipadamente é resultado do plantio em época mais adequada e menos exposta ao patógeno causador da ferrugem asiática e outras doenças.

\section{Avaliação de produtividade em diferentes momentos de aplicação do fungicida}

A aplicação de fungicida de forma preventiva a instalação da doença no campo desencadeou menores perdas em produtividade, independentemente do intervalo de aplicação. Seguindo o constatado por VITTI, et al. 2004, que obteve maior período residual e melhor desempenho dos fungicidas devido a aplicação preventiva. Da mesma forma por OLIVEIRA, 2004 que constatou um aumento de rendimento de até 100\% quando realizada a aplicação preventiva. 
Conforme observado pelo teste de Tukey $(\mathrm{P} \leq 5 \%$ ), a maior produtividade observada foi para o momento de aplicação do fungicida 3 (aplicação baseada na fenologia da planta). Os momentos de aplicação do fungicida 2 (tratamento baseado em DAE), 4 (tratamento baseado em DAE +7 dias de atraso) e 5 (tratamento baseado na fenologia +7 dias de atraso) não diferenciaram significativamente entre o tratamento 3 (baseado na fenologia da planta) e nem diferenciaram significativamente entre o tratamento 1 (testemunha). $\mathrm{O}$ momento de aplicação do fungicida 1 (testemunha) apresentou a pior produtividade (Tabela 7).

Tabela 7. Produtividade (kg/ha) de grãos de soja e área abaixo da curva de progresso da doença (AACPD) nos diferentes tratamentos $(\mathrm{T})$.

\begin{tabular}{cccc}
\hline T & Base de aplicação de fungicida & kg/ha & AACPD** \\
\hline 1 & Testemunha & $3740,2 \mathrm{~b}^{*}$ & $2734,2 \mathrm{a}$ \\
2 & Baseado em dias após a emergência (DAE) & $4140,3 \mathrm{ab}$ & $1396,5 \mathrm{bc}$ \\
3 & Baseado na fenologia da planta (FP) & $4227,2 \mathrm{a}$ & $1157,9 \mathrm{c}$ \\
4 & Baseado em DAE + 7 dias de atraso & $4040,9 \mathrm{ab}$ & $1958,3 \mathrm{~b}$ \\
5 & Baseado na FP + 7 dias de atraso & $4052,2 \mathrm{ab} * * *$ & $1378,2 \mathrm{bc}^{* * *}$
\end{tabular}

*Médias da coluna seguidas por letras iguais não diferem entre pelo Teste de Tukey $(\mathrm{P} \leq 5 \%)$; ** Área Abaixo da Curva de Progresso da ferrugem em função da severidade da doença em \% de área foliar afetada; *** $\mathrm{Na}$ análise de produtividade, foram consideradas as seis épocas de semeadura e na análise de AACPD foram consideradas as épocas de semeadura de 2 a 6.

Indo ao encontro do constatado por GODOY et al. (2009), as aplicações sequenciais com base na fenologia da planta apresentam redução na severidade da ferrugem asiática e maior produtividade da planta. NAVARINI et al. (2007) também observou uma tendência de maior ganho de rendimentos estarem relacionados a aplicações baseadas na fenologia da planta.

Porém, REIS et al. (2007) verificou que o controle de ferrugem baseado no estádio fenológico da cultura pode não ser eficiente visto que o patógeno pode se instalar em qualquer estágio fenológico. Porém no ensaio, todas as aplicações foram baseadas no principio da proteção, motivo pelo qual pode ter influenciado no resultado de retorno positivo a aplicação baseada na fenologia (Momento 3).

Atrasos na aplicação do fungicida de proteção causam redução significativa na produção média por hectare. É possível constatar que a escolha pelos momentos de aplicação do fungicida 4 e 5 ( baseado em DAE +7 dias de atraso e baseado na 
fenologia +7 dias de atraso, respectivamente) causariam uma redução de cerca de 3 sacas $(60 \mathrm{~kg})$ por hectare. Já para a escolha do momento de aplicação do fungicida 2 (baseado em DAE) causaria uma redução de 1 saca $(60 \mathrm{~kg})$ por hectare. Diferença maior é a observada entre a decisão de não aplicação de fungicida para controle da ferrugem ( momento de aplicação 1) e a aplicação baseada na fenologia da planta. A testemunha apresentou uma redução de cerca de 8 sacas $(60 \mathrm{~kg})$ por hectare em comparação a parcela tratada com aplicação baseada na fenologia.

\section{AVALIAÇÃO DA ÁREA ABAIXO DA CURVA DE PROGRESSO DA DOENÇA (AACPD)}

\section{Avaliação de AACPD comparando as diferentes épocas de plantio}

A primeira época plantada (semeadura em 16/11/2014) encontrava-se em R8 quando foi constatada a primeira pústula de ferrugem. As plantas já se encontravam em fase de desfolha, o que influenciaria na análise da severidade e resultaria numa avaliação incorreta. Assim, não foi possível realizar a avaliação de severidade da semeadura realizada em 16/11/2015.

A decisão de avaliação da severidade da doença com base na área abaixo da curva de progresso da doença (AACPD) se deve pelo fato que essa análise permite uma avaliação mais estável e menos afetada pelo tempo de análise e variações ambientais (CAMPBEL; MADDEN, 1990).

A semeadura realizada em 02/01/2015 (quinta época plantada) apresentou a maior severidade em comparação às demais épocas plantadas (Tabela 6). A semeadura em 18/12/2014 (quarta época plantada) não diferenciou significativamente da época semeada em 02/01/2015 (quinta época plantada) nem das semeaduras realizadas em 11/12/2014 e 06/01/2015 (terceira e sexta épocas plantadas, respectivamente). A parcela semeada em 28/11/2014 apresentou a menor severidade dentre as parcelas e não apresentou diferença significativa entre as semeaduras em 11/12/2014 e 06/01/2015 (terceira e sexta épocas plantadas, respectivamente)

Um maior volume de chuvas no final de ciclo e a introdução da doença cada vez mais precoce propiciaram a maior severidade observada nas parcelas plantadas tardiamente. Um clima mais favorável ao desenvolvimento do fungo pode ter causado uma maior severidade constatada na quinta época plantada (em 02/01/2015). 
Como esperado, a semeadura realizada em 28/11/2014 apresentou a menor severidade, isto porque a ferrugem foi constatada no estádio fenológico R6, no fim do ciclo reprodutivo, próximo a colheita, estando sujeito a menor pressão do inóculo durante o desenvolvimento da planta, em comparação as demais épocas plantadas (Tabela 4). Além disso, nesta época de semeadura o hospedeiro esta sujeito a menor pressão de inóculo do patógeno (SILVA et al., 2007).

\section{Avaliação de AACPD em diferentes momentos de aplicação do fungicida}

O momento de aplicação de fungicida 1 (testemunha) apresentou maior severidade em comparação aos demais tratamentos. Os momento de aplicação de fungicida 2 ( baseado em DAE) , 4 ( baseado em DAE + 7 dias de atraso) e 5 (baseado na fenologia + 7 dias de atraso) não apresentaram diferenças significativas entre si. $\mathrm{O}$ momento de aplicação de fungicida 5 (baseado na fenologia +7 dias de atraso) não diferenciou significativamente do momento de aplicação de fungicida 3 (baseado na fenologia). O momento de aplicação do fungicida 3 (aplicação baseada na fenologia) apresentou a menor severidade constatada entre os tratamentos aplicados (Tabela 7).

Foi constatada, visualmente, uma desfolha menos precoce no momento de aplicação de fungicida 3 (baseado na fenologia), seguido do momento de aplicação de fungicida 2 (baseado em DAE), 4 (baseado em DAE + 7 dias de atraso) , 5 (baseado na fenologia +7 dias de atraso) e 1 (testemunha), respectivamente. Durante as avaliações realizadas em campo, foi possível observar que o momento 3 (baseado na fenologia da planta) apresentava uma desfolha mais tardia em comparação aos demais tratamentos (Anexo 4). Como era esperado, o momento de aplicação de fungicida 1 testemunha) sofreu desfolha precoce, seguida dos demais tratamentos. Mas em todas as épocas plantadas era observado claramente que o momento de aplicação de fungicida 3 (baseado na fenologia da planta) apresentava uma desfolha mais tardia.

\section{CORRELAÇÃO ENTRE OS DADOS DE PRECIPITAÇÃO, SEVERIDADE (AACPD) E PRODUTIVIDADE (kg/ha)}

Não foi possível correlacionar os dados de precipitação total entre os os diferentes momentos de pulverização do fungicida devido ao fato que cada momento recebeu a mesma quantidade de chuva. Isto porque somente as diferentes épocas de semeadura 
receberam diferentes precipitações, já os tratamentos, por estarem localizados na mesma área experimental e por receberem o mesmo volume de chuvas, não apresentaram diferenças de precipitação entre si.

Tabela 8. Somatório do acumulado (SAC) de chuvas $(\mathrm{mm})$ em todo o ciclo da planta (do plantio a colheita), produtividade ( $\mathrm{kg} / \mathrm{ha}$ ) de grãos de soja e área abaixo da curva de progresso da doença (AACPD) constatados nas diferentes épocas de semeadura (EP).

\section{EP DS** DC $* * *$ SAC Grãos - kg/ha AACPD****}

\begin{tabular}{cccccc}
\hline 1 & $16 / 11 / 2014$ & $28 / 3 / 2015$ & 1052,2 & $4318,7 \mathrm{ab}$ & - \\
2 & $28 / 11 / 2014$ & $4 / 4 / 2015$ & 954,8 & $4785,3 \mathrm{a}$ & $1150,3 \mathrm{c}$ \\
3 & $11 / 12 / 2014$ & $11 / 4 / 2015$ & 908,2 & $4122,9 \mathrm{~b}$ & $1284,6 \mathrm{bc}$ \\
4 & $18 / 12 / 2014$ & $18 / 4 / 2015$ & 906,0 & $3985,4 \mathrm{~b}$ & $1984,9 \mathrm{ab}$ \\
5 & $2 / 1 / 2015$ & $25 / 4 / 2015$ & 819,6 & $3915,1 \mathrm{~b}$ & $2692,7 \mathrm{a}$ \\
6 & $6 / 1 / 2015$ & $25 / 4 / 2015$ & 810,2 & $3113,5 \mathrm{c}$ & $1512,6 \mathrm{bc}$ \\
\hline
\end{tabular}

*Médias da coluna seguidas por letras iguais não diferem entre pelo Teste de Tukey ao nível de 5\% de probabilidade de erro; ** Data de semeadura; *** Data da colheita; **** Área Abaixo da Curva de Progresso da ferrugem em função da severidade da doença em \% de área foliar afetada.

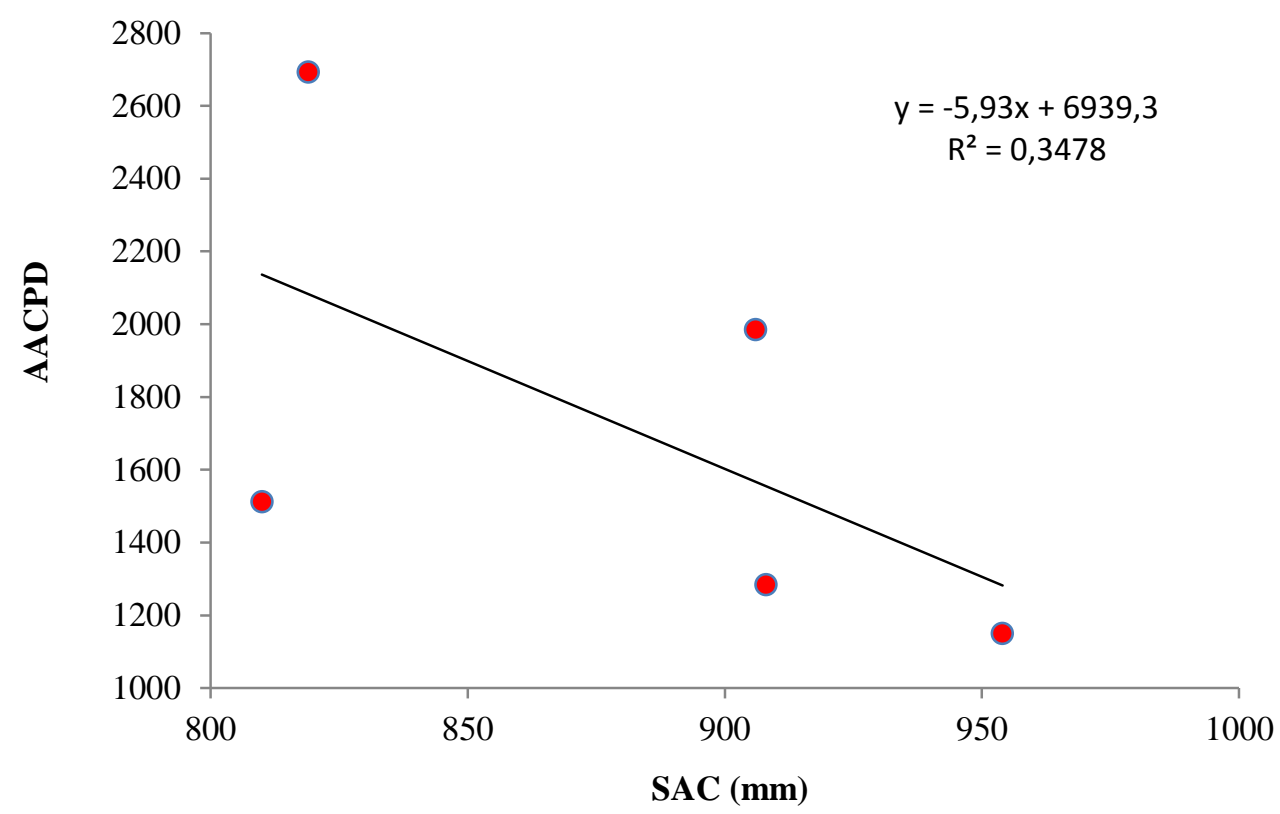

Figura 2. Regressão linear e coeficiente de determinação da correlação existente entre o somatório do acumulado de chuva (SAC) ocorrido durante todo ciclo da planta e a área abaixo da curva de progresso da doença (AACPD). *Variável dependente (y): Área abaixo da curva de progresso da doença constatada nas diferentes épocas de semeadura; **Variável independente (x): Precipitação total $(\mathrm{mm})$ constatada em todo ciclo da planta (do plantio a colheita) nas diferentes épocas plantadas. 


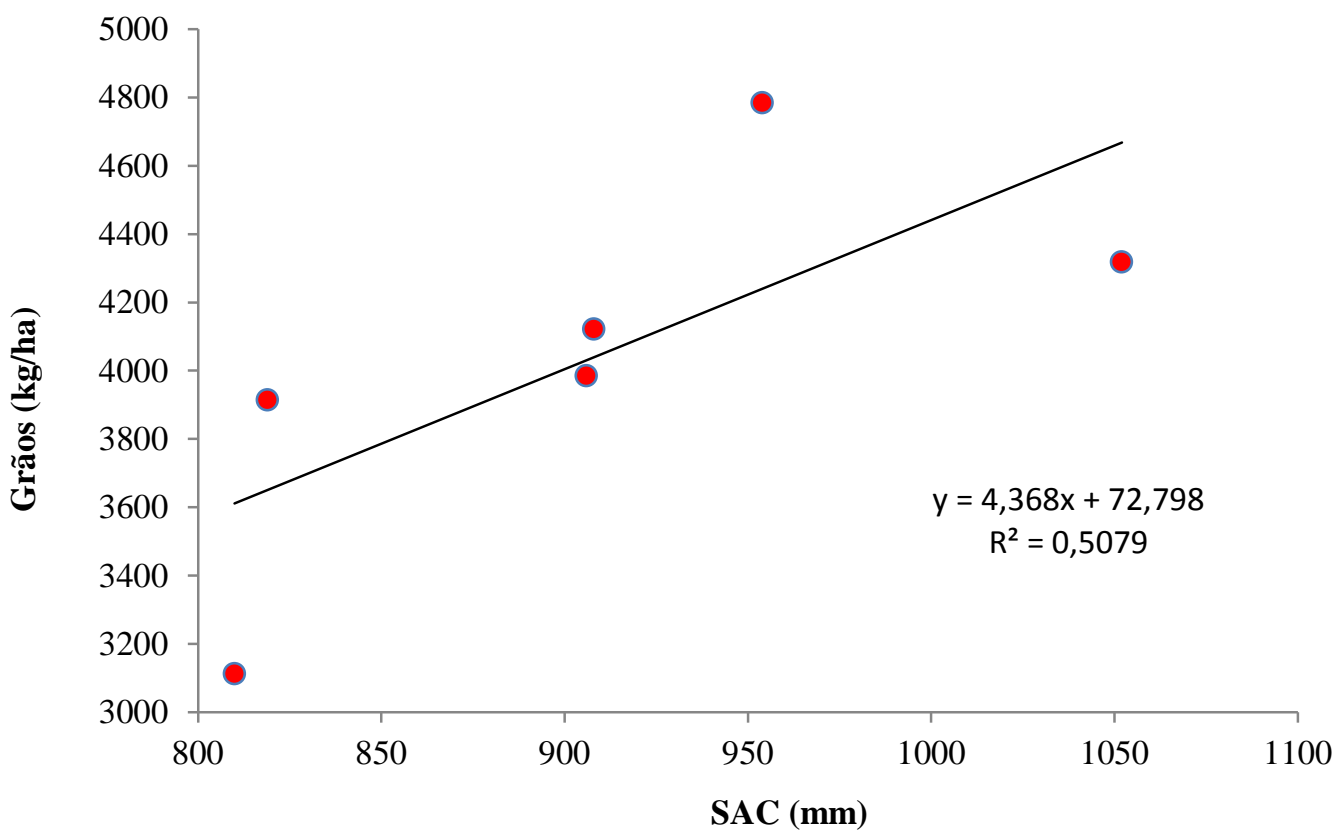

Figura 3. Regressão linear e coeficiente de determinação da correlação existente entre o somatório do acumulado de chuvas (SAC) ocorrido durante todo ciclo da planta (plantio a colheita) e a produtividade (kg/ha). *Variável dependente (y): Produtividade média $(\mathrm{kg} / \mathrm{ha})$ constatada nas diferentes épocas plantadas; **Variável independente (x): Precipitação total $(\mathrm{mm})$ constatada em todo ciclo da planta (do plantio a colheita) nas diferentes épocas de semeadura.

Foi constatada uma maior correlação existente entre a precipitação ocorrida em todo o ciclo da planta (do plantio a colheita) com a produtividade média (kg/ha), em comparação a correlação observada entre a precipitação ocorrida em todo ciclo da planta (do plantio a colheita) e a severidade (AACPD).

O coeficiente de determinação da correlação entre a precipitação total (do plantio a colheita) e a severidade (AACPD) é de 0,35, apresentando um coeficiente de correlação de $-0,59$. O que demonstra a correlação baixa e negativa entre os fatores precipitação em todo o ciclo da planta e a severidade, onde a redução da precipitação observada da data de plantio a colheita nas diferentes épocas plantadas provoca um aumento da severidade da doença. Entretanto, acredita-se que o fator: introdução da doença em estádio fenológico mais precoce seja principal fator causador do aumento de severidade observada ao longo das épocas de semeadura. Isto porque quanto mais precoce a introdução da doença, mais sujeito a pressão do inóculo do fungo. Como as parcelas foram plantadas nos meses de novembro de 2014 a início de janeiro de 2015 era esperada (devido à série histórica da região) a redução do volume de chuvas constatado ao longo dos meses de março e abril. Também era esperado o aumento da severidade ao 
longo das épocas de plantio visto que a introdução da primeira pústula de ferrugem foi constatada em estádio fenológico cada vez mais precoce, estando sujeitas, progressivamente, a maior pressão de inóculo do fungo.

Foi constatada uma maior correlação entre a precipitação ocorrida em todo o ciclo da planta (do plantio a colheita) e produtividade ( $\mathrm{kg} / \mathrm{ha}$ ) avaliada nas diferentes épocas plantadas. O coeficiente de determinação da correlação entre a precipitação total $(\mathrm{mm}) \mathrm{e}$ produtividade $(\mathrm{kg} / \mathrm{ha})$ é de 0,51 , apresentando um coeficiente de correlação de $0,70 . \mathrm{O}$ que demonstra uma maior e positiva correlação entre esses fatores. O aumento de precipitação provocou um aumento da produtividade média por época de semeadura. Porém, o fator precipitação não deve ser considerado isoladamente como o único fator causador do aumento da produtividade média. Fatores como introdução da primeira pústula, pressão de inóculo do fungo, entre outros fatores bióticos e abióticos podem ter influenciado nos resultados encontrados.

Acredita-se também que o fator precipitação tem maior influência sobre a severidade (AACPD), quando constatado o aumento do volume de precipitação em pontos críticos de desenvolvimento da planta (como nos estádios de enchimento do grão) e, principalmente, após a constatação da primeira pústula no campo. O fator chuva durante todo o ciclo de vida da planta pode influenciar na produtividade, porém, acredita-se que o fator chuva após a constatação da primeira pústula influencia o aumento na severidade da doença.

Para tanto, foi avaliada a correlação existente entre o volume total ( $\mathrm{mm})$ de chuvas ocorridas nas diferentes épocas plantadas a partir da constatação da primeira pústula de ferrugem no bloco com os dados de AACPD e produtividade estimada, demonstrados nas Figuras 4 e 5.

Foi constatada baixa e negativa correlação entre o somatório total do volume de chuvas nas diferentes épocas plantadas a partir da constatação da primeira pústula e a produtividade média. Porém, foi possível constatar a alta correlação entre os fatores somatório total do volume de chuvas nas diferentes épocas plantadas a partir da constatação da primeira pústula e a área abaixo da curva de progresso da doença.

O coeficiente de determinação da correlação existente o somatório do volume de chuvas $(\mathrm{mm})$ ocorridos a partir da constatação da primeira pústula e a produtividade $(\mathrm{kg} / \mathrm{ha})$ nas diferentes épocas de semeadura é de 0,26 , apresentando um coeficiente de correlação de - 0,51. Mostrando assim, que as precipitações ocorridas após a 
constatação da primeira pústula de ferrugem pouco influenciaram os resultados obtidos na análise de produtividade média por época de semeadura. As chuvas ocorridas ao longo de todo o ciclo da cultura (do plantio a colheita) foram o que realmente influenciaram nos dados obtidos na produtividade nas diferentes épocas de semeadura.

O coeficiente de determinação da correlação existente entre o somatório do volume de chuvas $(\mathrm{mm})$ ocorridos a partir da constatação da primeira pústula e a severidade (AACPD) nas diferentes épocas de semeadura é de 0,82 , apresentando um coeficiente de correlação de 0,90 . O que demonstrou a alta correlação existente entre as chuvas ocorridas após a constatação da primeira pústula e o aumento da severidade (medida na AACPD). As chuvas ao fim do ciclo da cultura e em áreas com a doença já introduzida contribuem para o aumento da severidade da ferrugem asiática da soja.

Assim é possível constatar que o somatório total do volume de chuvas durante todo ciclo da planta (da semeadura a colheita) nas diferentes épocas plantadas possui alta correlação ao fator ganho em produtividade (kg/ha). É possível constatar também que o somatório total do volume de chuvas a partir da constatação da primeira pústula nas diferentes épocas plantadas possui alta correlação ao fator aumento de severidade (AACPD).

Tabela 9. Somatório do acumulado de chuvas (SAC) (mm) ocorrido após a data de constatação da primeira pústula de ferrugem (DF); produtividade $(\mathrm{kg} / \mathrm{ha})$ e área abaixo da curva de progresso da doença (AACPD) constatada nas diferentes épocas plantadas (EP).

\begin{tabular}{cccccc}
\hline EP & DF & DC* & SAC* & Grãos-kg/ha & AACPD** \\
\hline 1 & $4 / 3 / 2015$ & $28 / 3 / 2015$ & 159,8 & 4318,7 & \\
2 & $6 / 3 / 2015$ & $4 / 4 / 2015$ & 199,0 & 4785,3 & 1150,3 \\
3 & $7 / 3 / 2015$ & $11 / 4 / 2015$ & 276,0 & 4122,9 & 1284,6 \\
4 & $14 / 3 / 2015$ & $18 / 4 / 2015$ & 304,2 & 3985,4 & 1984,7 \\
5 & $14 / 3 / 2015$ & $25 / 4 / 2015$ & 356,0 & 3915,1 & 2692,7 \\
6 & $21 / 3 / 2015$ & $25 / 4 / 2015$ & 275,6 & 3113,5 & 1512,6 \\
\hline
\end{tabular}

*Data da colheita ** área abaixo da curva de progresso da doença 


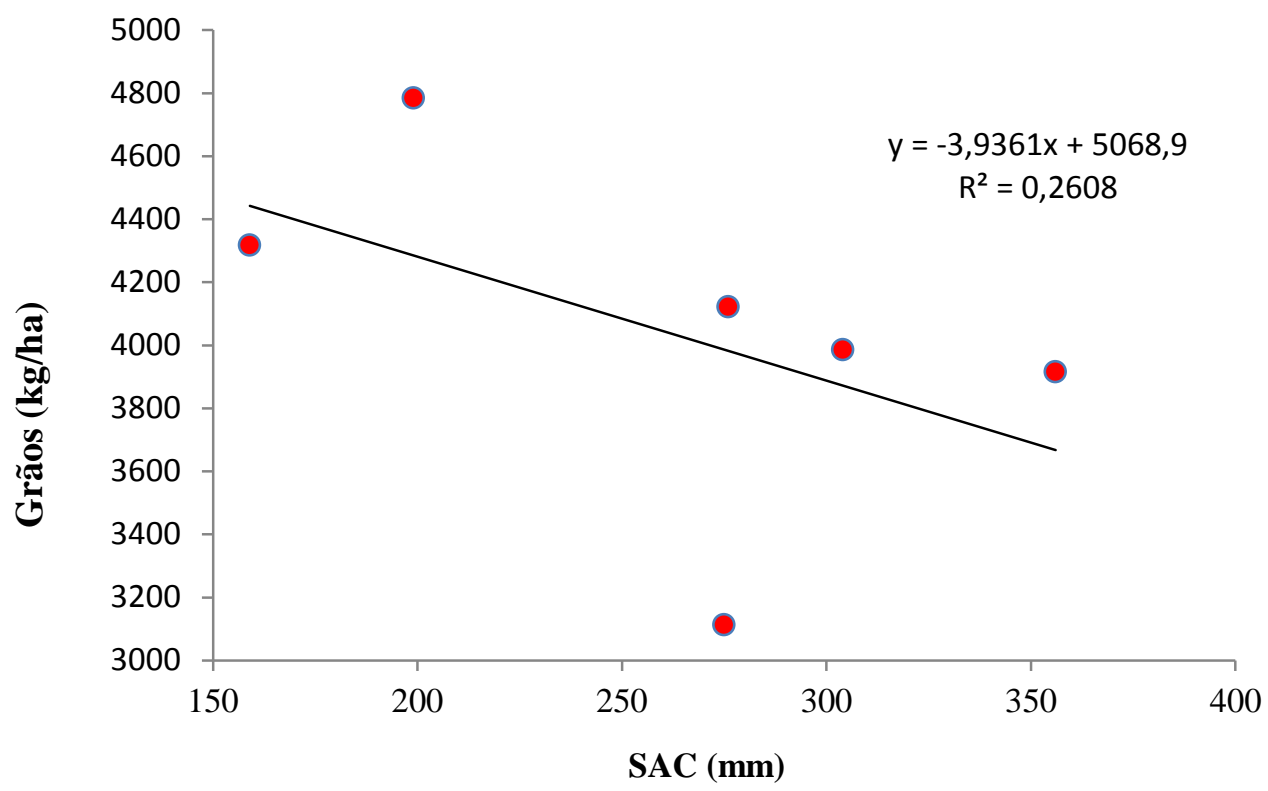

Figura 4. Regressão linear e coeficiente de determinação da correlação existente entre o somatório do acumulado de chuvas (SAC) ocorrido após a constatação da primeira pústula e a produtividade ( $\mathrm{kg} / \mathrm{ha})$. *Variável dependente (y): Produtividade média $(\mathrm{kg} / \mathrm{ha})$ constatadas nas diferentes épocas plantadas; **Variável independente (x): Precipitação total constatada após a introdução da primeira pústula nas diferentes épocas plantadas (mm).

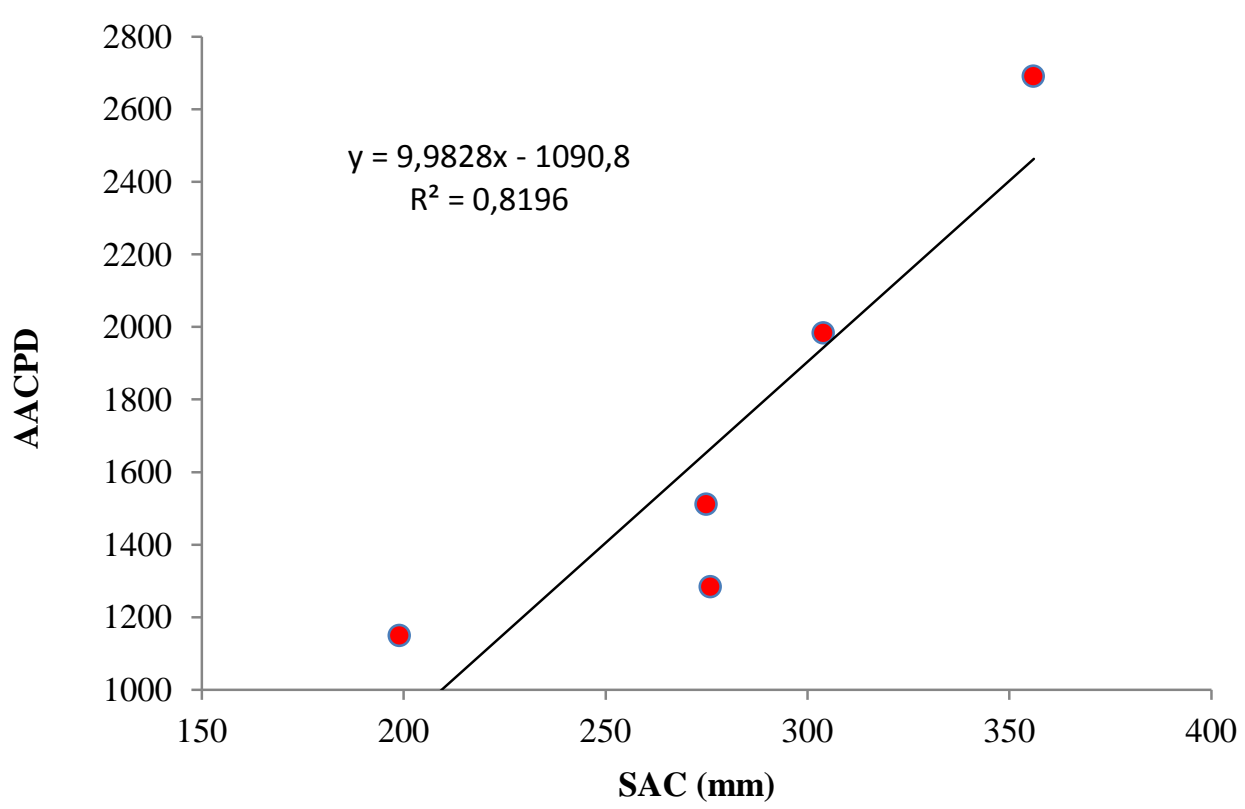

Figura 5. Regressão linear e coeficiente de determinação da correlação existente entre o somatório do acumulado de chuvas (SAC) ocorrido após a constatação da primeira pústula e a severidade (AACPD). *Variável dependente (y): AACPD constatada nas diferentes épocas de plantio; ** Variável independente (x): Precipitação total constatada após a introdução da primeira pústula nas diferentes épocas plantadas $(\mathrm{mm})$. 


\section{CORRELAÇÃO ENTRE OS RESULTADOS DE PRODUTIVIDADE E SEVERIDADE}

Os resultados obtidos relacionando as avaliações de severidade e produtividades demonstram a correlação negativa existente entre produtividade e severidade (Tabelas 6 e 7). Maiores severidades resultam em menores produtividades, formando uma correlação inversamente proporcional.

Foi constatada uma maior produtividade e menor severidade no tratamento de fungicida baseado na fenologia da planta. Conforme o constatado por GODOY et al. (2009) as aplicações sequenciais com base na fenologia da planta apresentaram redução na severidade da ferrugem asiática e maior produtividade da planta. Atrasos na aplicação, conforme realizado no momento de aplicação de fungicida 5, reduzem a produtividade e aumentam a severidade da doença.

Já REIS et al. (2007) verificaram que o controle de ferrugem baseado no estádio fenológico da cultura pode não ser eficiente visto que o patógeno pode se instalar em qualquer estágio fenológico. Porém no ensaio, todas as aplicações foram baseadas no principio da proteção, motivo pelo qual pode ter influenciado no resultado de retorno positivo a aplicação baseada na fenologia.

Assim, entende-se que o acompanhamento da lavoura é fundamental para monitoramento e tomada de decisão de quando e quanto aplicar o fungicida. Nas condições observadas no Distrito Federal, a aplicação baseada na fenologia da planta resulta na maior produtividade por hectare e menor severidade da doença. Plantios precoces proporcionam menor pressão de inóculo do patógeno, menor severidade e maior produtividade estimada. 


\section{CONCLUSÃO}

1. A aplicação de fungicida baseada na fenologia da planta resultou na maior produtividade e menor severidade. Para a região do Distrito Federal, a escolha do momento de aplicação de fungicida baseado na fenologia da planta, resultou em menor severidade e maior produtividades estimadas.;

2. Plantios tardios aumentam a severidade da Ferrugem asiática da soja e resultaram na redução da produtividade estimada;

3. O plantio realizado em 28/11/2014 (segunda época plantada) resultou em maiores produtividades e menores severidades;

4. O plantio realizado em 06/01/2015 (sexta época plantada) resultou na menor produtividade (redução de cerca de 27 sacas por hectare);

5. Atrasos de sete dias na decisão de aplicação do fungicida resultam no aumento da severidade da Ferrugem asiática da soja e na redução da produtividade em cerca de 3 sacas de $60 \mathrm{~kg}$ por hectare;

6. A não aplicação de fungicida resultou na redução de produtividade em cerca de 8 sacas de $60 \mathrm{~kg}$ por hectare;

7. Precipitações ocorridas ao longo de todo ciclo da planta (da semeadura a colheita) influenciaram nos resultados obtidos na análise de produtividade. Um maior volume de precipitações ocorridas ao longo de todo o ciclo de vida da planta (da semeadura a colheita) resulta em maiores produtividades;

8. Precipitações ocorridas da constatação da primeira pústula a colheita mostraram grande correlação aos resultados obtidos na análise de severidade. Maior volume de precipitação ocorrida após a constatação da primeira pústula proporcionou ambiente mais propício ao desenvolvimento do fungo e consequente aumento de severidade. 


\section{REFERÊNCIAS}

ALVES, S.A.M.; FURTADO, G.Q.; BERGAMIN FILHO, A. Influência das condições climáticas sobre a ferrugem da soja. In: Zambolim L (Ed.). Ferrugem asiática da soja. Viçosa MG. Suprema Gráfica e Editora Ltda, p. 37-59, 2006.

BUTZEN, S; MARCON, A; MCINNES, B; SCHUH, W. Asian soybean rust: fungicide application technology. Crop Insights, Johnston, v. 15, n. 1, p. 1-6, 2005.

CALAÇA, H.A. Ferrugem asiática da soja: relações entre o atraso do controle químico, rendimento, severidade e área foliar sadia de soja (Glycine max L. Merrill). Piracicaba, 2007. 80p.: II. Dissertação (Mestrado). ESALQ/USP, 2007.

CALDWELL, P.; LAING, M. Soybean rust - a new disease on the move. 2002. Disponível em: http://www.saspp.org/archieved/tablesoybeanrust. Acesso em 14 de março de 2015.

CÂMARA, G.M.S.; SEDIYAMA, T.; DOURADO-NETO, D.; BERNARDES, M.S. Influence of photoperiod and air temperature on the growth, flowering and maturation of soybean (Glycine max (L.) Merrill). Scientia Agricola, v. 54, p. 149-154, 1997.

CAMPBELL, C. L.; MADDEN, L. V. Introduction to plant disease epidemiology. New York: John Wiley \& Sons, p. 107-128, 1990.

COMPANHIA NACIONAL DE ABASTECIMENTO. Acompanhamento da safra brasileira de grãos, v. 2 - Safra 2014/15, n. 9 - Nono levantamento, junho 2015. Brasília: Conab. Disponível

em: http://www.conab.gov.br/conteudos.php?a=1253\&t=2\&Pagina_objcmsconteudos=2\#A objcmsconteudos . Acesso em 01 de outubro de 2015.

DAROISH, M.; HASSAN, Z.; AHAD, M. Influence os Planting Dates and Plant Densities on Photosynthesis Capacity, Grain and Biological Yeld of Soybean [Glycine $\max ($ L.) Merr.] in Karaj, Iran. Journal of Agronomy, Tehran, v.4, n.3, p.230-237. 2005. 
DEL PONTE, E. M.; GODOY, C.V.; LI, X.; YANG, X.B. Predicting severity of Asian soybean rust epidemics with empirical rainfall models. Phytopathology, v. 96, p.797803, 2006.

DESLANDES, J.A. Ferrugem da soja e de outras leguminosas causadas por Phakopsora pachyyrhizi no Estado de Minas Gerais, Fitopatologia Brasileira v.4, p.337339, 1979.

EBONE, A.; DEL FRARI, B.K.; PATIAS, D.; STEFANELLO, M.T.; SERAFINI, P.T.; MINUZZI, G.; GAI, R.P.; BALARDIN, R.S. Eficiência de fungicidas de diferentes grupos químicos no controle de ferrugem asiática da soja. In: XVI Simpósio de Ensino, Pesquisa e Extensão. Santa Maria, RS, 2012.

GARCIA, A. Estudo do índice de colheita e de outras características agronômicas de dez cultivares de soja, Glycine max (L.) Merrill, e de suas correlações com a produção de grãos, em duas épocas de semeadura. Dissertação (Mestrado em Agronomia), Universidade Federal de Viçosa, Viçosa-MG. 1979. 69 p.

GIORDANI, R. F. Controle de oídio e doenças de final e ciclo na cultura da soja. 2001. 57p. Dissertação (Mestrado em Agronomia) - Universidade Federal de Santa Maria, Santa Maria - RS.

GODOY, C.; UTIAMADA, C; SILVA, L.H.; SIQUERI, F. Ensaios de fungicidade realizados na safra 2009/10 para avaliar a ação de misturas triazóis e estrobilurinas frente à ferrugem asiática da soja. Revista Cultivar Grandes Culturas.v. 34, p. 055-056. 2010.

GODOY, C.V.; CANTERI, M.G. Efeitos protetor, curativo e erradicante de fungicidas no controle da ferrugem da soja causada por Phakopsora pachyrhizi, em casa de vegetação. Fitopatologia Brasileira v. 29, p.097-101, 2004. 
GODOY, C.V;. FLAUSINO, A.M.; SANTOS, L.C.M.; DEL PONTE, E.M. Eficiência do controle da ferrugem asiática da soja em função do momento de aplicação sob condições de epidemia em Londrina, PR. Tropical Plant Pathology, v.34, n.1, p.56-61, 2009.

KOMORI, E.; HAMAWAKI, O.T.; SOUZA, M.P.; SHIGIHARA, D.; BATISTA, A.M. Influência da época de semeadura e população de plantas sobre características agronômicas na cultura da soja. Bioscience Journal, v.20, n.3, p.13-19, 2004

LEVY, C. Epidemiology and chemical control of soybean rust in southern Africa. Plant Disease v. 89, p. 669-674, 2005.

MARCHIORI, L. F. S; CÂMARA, G. M. S; PEIXOTO, C.P; MARTINS, M. C. Desempenho vegetativo de cultivares de soja [Glycine max (L.) Merrill] em épocas normal e safrinha. Scientia Agricola, v. 56, n.2, p.383-390, 1999.

MARTINS, M.C.; CÂMARA, G.M.S.; PEIXOTO, C.P.; MARCHIORI, L.F.S.; LEONARDO, V.; MATTIAZZI, P. Épocas de semeadura, densidades de plantas e desempenho vegetativo de cultivares de soja. Scientia Agricola, v.56, n.4, p.851-858, 1999.

MELCHING, J.S.; DOWLER, W.M.; KOOGLE, D.L.; ROYER, M.H. Effect of duration, frequency, and temperature of leaf wetness period on soybean rust. Plant Disease, v.73, p.117-122, 1989.

MICHEL, C. A.; TOLEDO, H; PEREIRA, M. J. Z.; PEREIRA, N. M. Z. Reação de genótipos de soja a doenças foliares de final de ciclo. Anais, XXVIII Reunião de Pesquisa de Soja da Região Sul, Santa Maria, RS. 2000. p. 116.

MILES, M.R.; LEVY, C.; HARTMAN, G.L. Summary of the USDA fungicide efficacy trials to control soybean rust in Zimbabwe 2003- 2004. Integrated Pest Management Reviews, Zimbabwe, 2004. 
MOREL, W. Roya de la soja. Itapúa: Paraguay. Ministerio de Agricultura y Ganaderia. Subsecretaria de Agricultura, Dirección de Investigación Agrícola. Centro de Investigación Agrícola (CRIA) Capitan Miranda. Comunicado Phakopsora pachyrhizi Sydow) na cultura da soja. Summa Phytopathologica, v.33, n.2, p.182-186, 2007.

MUELlER, T. A.; MILES, M. R.; MOREL, W.; MAROIS, J. J.; WRIGHT, D. L.; KEMERAIT, R. C.; LEVY, C.; HARTMAN, G. L. Effect of fungicide and timing of application on soybean rust severity and yield. Plant Disease. v. 93, p. 243-248, 2009.

NAVARINI, L.; DALLAGNOL, L. J.; BALARDIN, R.S.; MOREIRA, M.T.; MENEGHETTI, R.C.; MADOLOSSO, M. G. Controle químico da ferrugem asiática (Phakopsora pachyrhizi Sydow) na cultura da soja. Summa Phytopathologica, v.33, n.2, p.182-186, 2007.

NAVARRO, J. C.; NAKASATO, R.; UTIAMADA, C.M.; YORINORI, J.T. First report of Asian soybean rust in Bolivia. Proceedings VII World Soybean Research Conference, IV International Soybean Processing and Utilization Conference, III Congresso Brasileiro de Soja, Foz do Iguaçu, 2004, p. 85- 86.

OLIVEIRA, A.B. Fenologia, desenvolvimento e produtividade de cultivares de soja em função de épocas de semeadura e densidades de plantas. Dissertação (mestrado) Universidade Estadual Paulista, Faculdade de Ciências Agrárias e Veterinárias, 2010.

OLIVEIRA, A.C.B.; GODOY, C.V.; MARTINS, M.C. Avaliação da tolerância de cultivares de soja à ferrugem asiática no Oeste da Bahia. Fitopatologia Brasileira v. 30, p. 658-662, 2005.

OLIVEIRA, S.H.F. Época de aplicação de fungicidas no controle da ferrugem asiática (Phakopsora pachyrhizi) da soja. Fitopatologia Brasileira, v. 29 Supl. p. 295, 2004.

PEIXOTO, C.P.; CÂMARA, G.M.S.; MARTINS, M.C.; MARCHIORI, L.F.S.; GUERZONI, R.A.; MATTIAZZI, P. Épocas de semeadura e densidade de plantas de 
soja: I. Componentes da produção e rendimento de grãos. Scientia Agricola, v.57, n.1, p. 89-96, 2000.

PENDletON, J. W; HARTWiG, E. E. Manegement. In: CALDWELL, B. E. (Ed.). Soybeans: improvement, production, and uses. Madison, Wisconsin, USA: American Society of Agronomy, 1973. p. 211-237.

PEREIRA, R.; FUJINO, M.; GUERZONI, R. Avaliação do fungicida FOX® , em pulverizações foliares, para o controle de mancha-alvo causada por Corynespora cassiicola na cultura da soja. $45^{\circ}$ Congresso Brasileiro de Fitopatologia. Manaus, 2012.

PINTO, F. F.; UEBEL, J. D; FOGGIATO, L.; EBONE, A.; SERAFINI, P. T.; DALLA FAVERA, D.; BALARDIN, R. S. Resposta de cultivares ao controle erradicante da ferrugem asiática da soja (Phakopsora pachyrhizi). In: Congresso Brasileiro de Soja. Cuiabá, MT, 2012.

PRADO, E. P; RAETANO, C. G; AGUIAR JÚNIOR, H. O; DAL POGETTO, M.H.F.A; CHRISTOVAM, R.S; GIMENES, M. J; ARAÚJO, D. Velocidade do ar em barra de pulverização na deposição da calda fungicida, severidade da ferrugem asiática e produtividade da soja. Summa Phytopathologica, v.36, n.1, p.45-50, 2010.

REIS, E. M.; LIMA NETO, V. C.; GODOY, C. V.; ROSA, C. T; CASTANHO, H. E. Controle químico da ferrugem asiática da soja na região sul do Paraná. Scientia Agraria, Curitiba, v. 8, n.3, p. 25, 2007.

RUPE, J.; SCONYERS, L. Soybean Rust. The Plant Health Instructor. American Phytopathological Society. Disponível em: <http://www.apsnet.org/edcenter/intropp/ lessons/fungi/Basidiomycetes/Pages/SoybeanRust.aspx>. Acesso em 09 de setembro de 2015.

SILVA, F.A.S.E.; AZEVEDO, C.A.V. A New Version of TheAssistat-Statistical Assistance Software. In: WORLD CONGRESS ON COMPUTERS IN 
AGRICULTURE, 4, Orlando-FL-USA: Anais... Orlando: American Society of Agricultural and Biological Engineers, 2006. p.393-396.

SILVA, F.A.S.E.; AZEVEDO, C.A.V. Versão do programa computacional Assistat para o sistema operacional Windows. Revista Brasileira de Produtos Agroindustriais, Campina Grande, v.4, n.1, p. 71-78, 2002.

SILVA, F.A.S.E.; AZEVEDO, C.A.V. Principal Components Analysis in the Software Assistat-Statistical Attendance. In: WORLD CONGRESS ON COMPUTERS IN AGRICULTURE, 7, Reno-NV-USA: American Society of Agricultural and Biological Engineers, 2009.

SILVA, F.A.S.E. The ASSISTAT Software: statistical assistance. In: INTERNATIONAL ONFERENCE ON COMPUTERS IN AGRICULTURE，6, Cancun, 1996. Anais... Cancun: American Society of Agricultural Engineers, 1996. p. 294-298.

SILVA, V. A. S; JULIATTI, F.C; SILVA, L.A. Interação entre resistência genética parcial e fungicidas no controle da ferrugem asiática da soja. Pesquisa Agropecuária Brasileira, Brasília, v.42, n.9, p.1261-1268, 2007.

SINCLAIR, J. B; HARTMAN, G. L. Soybean rust. In: HARTMAN, G. L.; SINCLAIR, J. B.; RUPE, J. C. (Ed.). Compendium of soybean diseases. 4th ed. St. Paul: American Phytopathological Society Press, 1999. p. 25-26.

SOARES, R. M; RUBIN, S. S. L; WIELEWICK, A. P; OZELAME, J. G. Fungicidas no controle da ferrugem Asiática (Phakopsora pachyrhizi) e produtividade em soja. Ciência Rural v. 34, p.1245- 1247, 2004.

TSCHANZ, A.T. Soybean rust epidemiology: Final Report. Asian Vegetable Research and Development Center, Shanhua, Taiwan.1984. 
VITTI, A. J; PAIVA, S.B; CASTRRO, R.M; VEIGA, J.S; GARCIA, L. Efeito residual e curativo de fungicidas para o controle de ferrugem da soja (Phakopsora pachyrhizi). Fitopatologia Brasileira, Brasília, v.29, Supl. p. 290, 2004.

WHETZEL, H. H. The terminology of phytopathology. Proc. Int. Congr. Plant Sciences, v.2, 1929.

WHETZEL, H. H.; HESLER, L.R.; GREGORY, C.T.; RANKIN, W.H. Laboratory outlines in plant pathology. Philadelphia: W.B. Saunders, 1925.

YORINORI, J. T.; NUNES JUNIOR J.; LAZZAROTTO, J. J. Ferrugem “Asiática” da soja no Brasil: evolução, importância econômica e controle. Londrina PR. Embrapa Soja, Documentos 247. 2004.

YORINORI, J. T. Ferrugem asiática da soja (Phakopsora pachyrhizi): ocorrência no Brasil e estratégias de manejo. In: Encontro brasileiro sobre doenças da cultura da soja, 2, 2002. Aldeia Norte Editora, 2002. p.47-54.

YORINORI, J.T; YORINORI, M. A.; GODOY, C. V. Evolução da ferrugem da soja (Phakopsora pachyrhizi) no Brasil, de 2001 a 2003. Fitopatologia Brasileira, v.28, p. S210, 2003.

YORINORI, J.T; YORINORI, M.A.; GODOY, C.V. Seleção de cultivares de soja resistentes à ferrugem "asiática” (Phakopsora pachyrhizi). Anais, XXX Reunião Sul de Soja da Região Sul. Cruz Alta, RS. 2002. p.94.

YORINORI, J.T; WILFRIDO, M. P. Ferrugem da soja: Phakopsora pachyrhizi Sydow. Londrina: Embrapa Soja, 2002. 


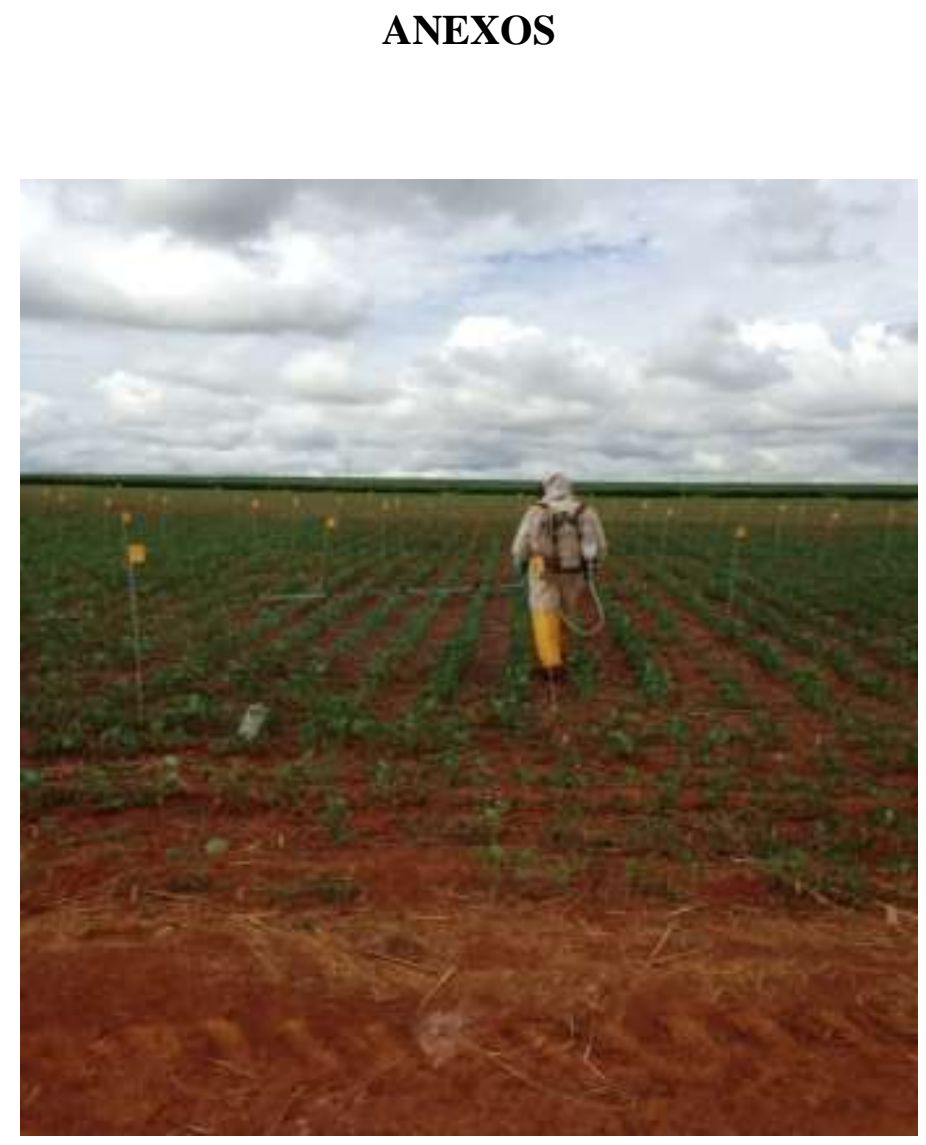

ANEXO 1. Aplicação do fungicida na área experimental com pulverizador pressurizado por $\mathrm{CO}_{2}$

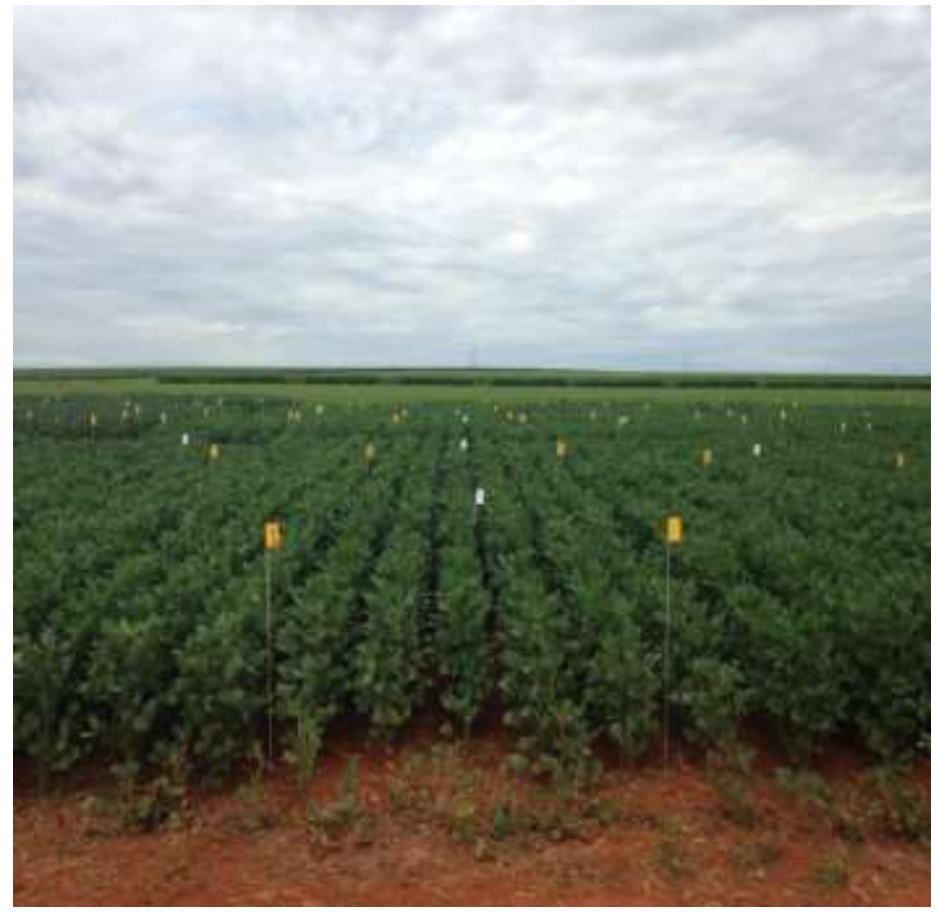

ANEXO 2. Disposição das parcelas no campo experimental do Instituto Phytos.

*A separação entre parcelas foi feita com o auxílio de estacas na coloração amarela. Foi fixada estaca na coloração branca no meio da parcela, onde foram avaliadas a planta demarcada pela estaca, as duas 
anteriores e as duas posteriores para análise de severidade. Quando constatada a primeira pústula de ferrugem, a parcela era sinalizada com estaca na coloração vermelha.

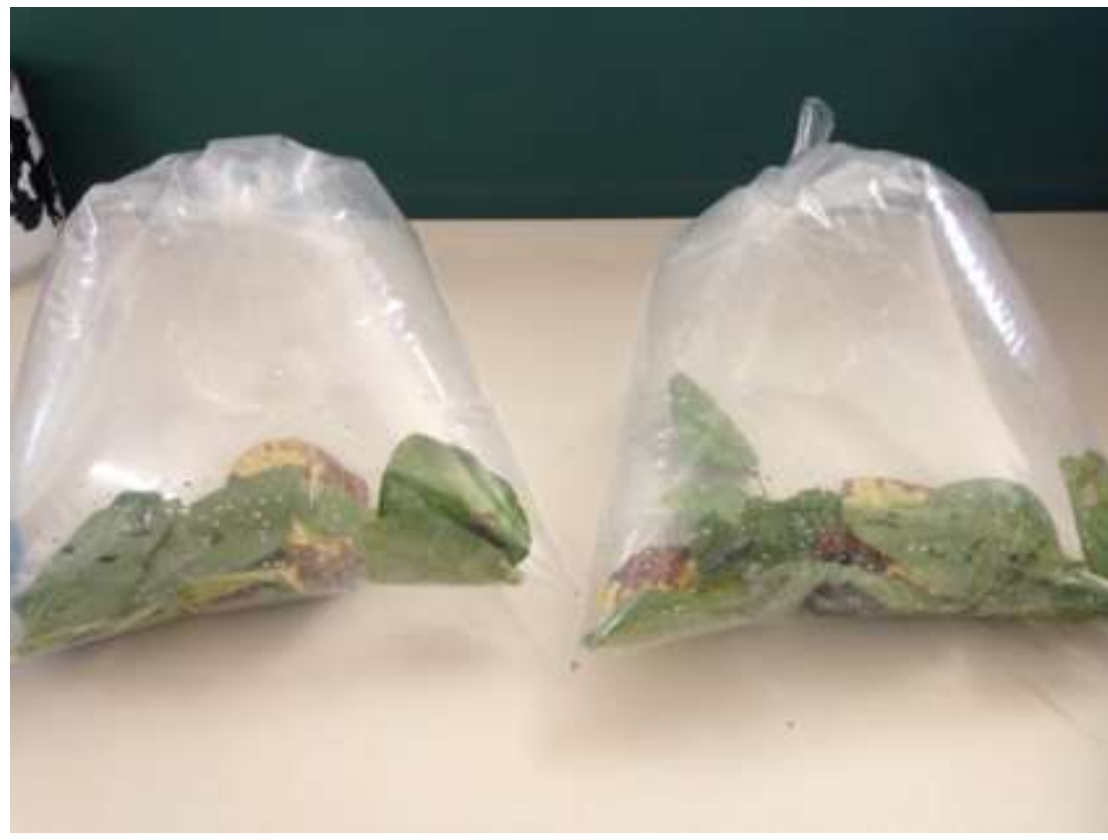

ANEXO 3. Câmara úmida para análise de primeira pústula de ferrugem asiática da soja nas diferentes épocas semeadas.

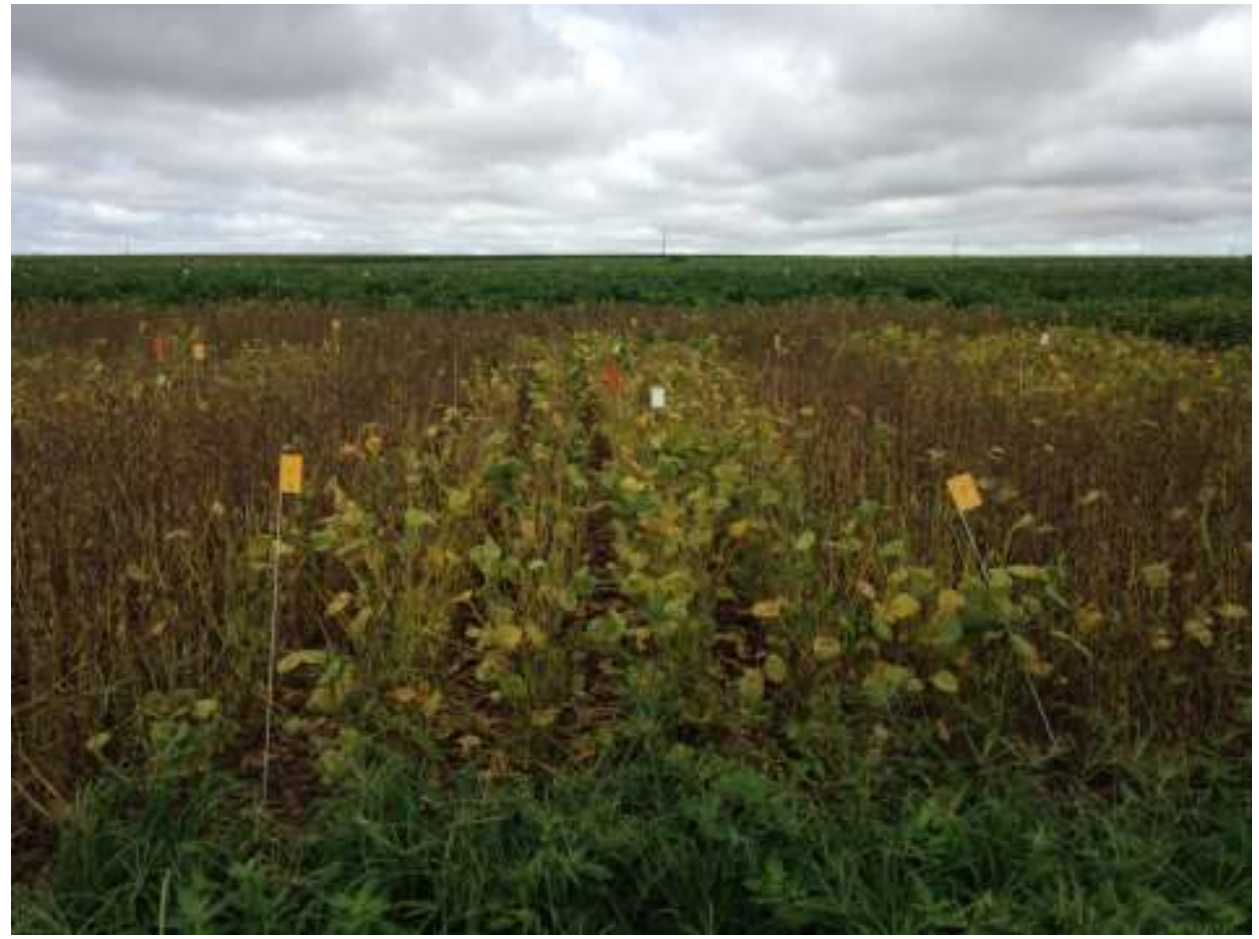

ANEXO 4. Diferença da desfolha mais tardia observada no Tratamento com aplicação de fungicida baseado na fenologia da planta (Tratamento 3).*A campo, o tratamento 3 
apresentou, em todas as épocas semeadas, desfolha mais tardia comparada aos demais tratamentos.

Tabela 10. Quadro de análise Produtividade (kg/ha), delineamento experimental em blocos casualizados. A parcela principal corresponde às 6 épocas de plantio e às secundárias aos 5 tratamentos.

\begin{tabular}{cccccc}
\hline FV & GL & SQ & QM & F & \\
\hline Blocos*** & 5 & 7585331,3 & 1517066,3 & 22,5 & $* *$ \\
Tratamentos & 4 & 810911,4 & 202727,8 & 3,0 & $*$ \\
Resíduo & 20 & 1345666,7 & 67283,3 & & \\
\hline Total & 29 & 9741909,4 & & & \\
\hline
\end{tabular}

* significativo ao nível de $5 \%$ de probabilidade de erro; ns não significativo $(\mathrm{p}>=0,5)$; ** significativo ao nível de $1 \%$ de probabilidade; $* * *$ Os blocos correspondem às diferentes épocas de plantio

Tabela 11. Quadro de análise AACPD (Área abaixo da curva de progresso da doença), delineamento experimental em blocos casualizados. A parcela principal corresponde às 5épocas de plantio e a secundária, os 5 tratamentos.

\begin{tabular}{cccccc}
\hline FV & GL & SQ & QM & F & \\
\hline Blocos* $^{*}$ & 4 & 7865698,9 & 1966424,7 & 13,7 & $* *$ \\
Tratamentos & 4 & 8112743,5 & 2028185,9 & 14,2 & $* *$ \\
Resíduo & 16 & 2286970,2 & 142935,6 & & \\
\hline Total & 24 & 18265412,6 & & & \\
\hline
\end{tabular}

* significativo ao nível de 5\% de probabilidade de erro; ** significativo ao nível de $1 \%$ de probabilidade; ns não significativo $(\mathrm{p}>=.05)$; ***Os blocos correspondem às diferentes épocas de plantio

Tabela 12. Quadro de análise da Taxa de progresso da doença, delineamento experimental em blocos casualizados. A parcela principal corresponde às 5épocas de plantio e a secundária, os 5 tratamentos.

\begin{tabular}{cccccc}
\hline FV & GL & SQ & QM & F & \\
\hline Blocos*** & 4 & 0,14 & 0,04 & 17,1 & $* *$ \\
Tratamentos & 4 & 0,05 & 0,01 & 6,28 & $* *$ \\
Resíduo & 16 & 0,03 & 0,002 & & \\
\hline Total & 24 & 0,22 & &
\end{tabular}

* significativo ao nível de 5\% de probabilidade de erro;** significativo ao nível de $1 \%$ de probabilidade; ns não significativo ( $\mathrm{p}>=.05$ ); *** Os blocos correspondem às diferentes épocas de plantio

Tabela 13. Resultado da análise de solo da área experimental

\begin{tabular}{|c|c|c|c|c|c|c|c|c|c|c|c|c|c|}
\hline \multirow{2}{*}{ PF* $^{*}$} & pH & $\mathbf{V}$ & $\mathbf{m}$ & \multirow{2}{*}{$\mathbf{T}$} & & \multirow{2}{*}{ SB } & $\mathbf{P}$ & $\mathbf{K}$ & $\mathbf{S}$ & $\mathbf{K}$ & $\mathbf{C a}$ & Mg & $\mathbf{H}+$ \\
\hline & $\mathrm{CaCl} 2$ & & & & & & \multicolumn{3}{|c|}{ mg dm-3 } & \multicolumn{4}{|c|}{ cmolc dm-3 } \\
\hline $0-10 \mathrm{c}$ & 5,3 & 63,4 & 0,30 & 12,0 & 7,6 & 7, & 34,2 & 160,0 & 5,0 & 0,4 & 5,1 & 2,1 & 4,4 \\
\hline $10-20 \mathrm{~cm}$ & 4,6 & 41,8 & 2,3 & 10,2 & 4,4 & 4,3 & 12,8 & 79,0 & 14,0 & 0,2 & 2,9 & 1,1 & 5,9 \\
\hline
\end{tabular}


*Profundidade.

Tabela 14. Média e somatório do acumulado de chuvas semanal (mm) constatada na estação meteorológica presente no experimento.

\begin{tabular}{|c|c|c|}
\hline Semana & Média (mm) & SAC \\
\hline 02/11/2014 a 08/11/2014 & 4,9 & 34,4 \\
\hline 09/11/2014 a 15/11/2014 & 17,7 & 123,6 \\
\hline $16 / 11 / 2014$ a $22 / 11 / 2014$ & 9,9 & 69,6 \\
\hline 23/11/2014 a 29/11/2014 & 14,9 & 104,2 \\
\hline $30 / 11 / 2014$ a 06/12/2014 & 9,7 & 67,6 \\
\hline 07/12/2014 a 13/12/2014 & 9,1 & 63,4 \\
\hline $14 / 12 / 2014$ a $20 / 12 / 2014$ & 13,3 & 93,4 \\
\hline 21/12/2014 a 27/12/2014 & 7,6 & 53,4 \\
\hline 28/12/2014 a 03/01/2015 & 8,0 & 56,0 \\
\hline 04/01/2015 a 10/01/2015 & 0,26 & 1,8 \\
\hline $11 / 01 / 2015$ a $17 / 01 / 2015$ & 0,11 & 0,81 \\
\hline $18 / 01 / 2015$ a $24 / 01 / 2015$ & 6,3 & 43,8 \\
\hline 25/01/2015 a 31/01/2015 & 3,2 & 22,4 \\
\hline 01/02/2015 a 07/02/2015 & 10,2 & 71,6 \\
\hline 08/02/2015 a 14/02/2015 & 0,23 & 1,6 \\
\hline $15 / 02 / 2015$ a $21 / 02 / 2015$ & 13,1 & 91,6 \\
\hline $22 / 02 / 2015$ a $28 / 02 / 2015$ & 16,7 & 117,0 \\
\hline 01/03/2015 a 07/03/2015 & 7,9 & 55,2 \\
\hline 08/03/2015 a 14/03/2015 & 7,0 & 49,2 \\
\hline $15 / 03 / 2015$ a $21 / 03 / 2015$ & 11,9 & 83,2 \\
\hline $22 / 03 / 2015$ a $28 / 03 / 2015$ & 0,91 & 6,4 \\
\hline 29/03/2015 a 04/04/2015 & 5,7 & 39,6 \\
\hline 05/04/2015 a $11 / 04 / 2015$ & 13,9 & 97,2 \\
\hline $12 / 04 / 2015$ a $18 / 04 / 2015$ & 10,9 & 76,2 \\
\hline $19 / 04 / 2015$ a $25 / 04 / 2015$ & 7,6 & 53,0 \\
\hline 26/04/2015 a 02/05/2015 & 3,8 & 26,6 \\
\hline 03/05/2015 a 09/05/2015 & 5,6 & 39,2 \\
\hline $10 / 05 / 2015$ a $16 / 05 / 2015$ & 0,4 & 3,0 \\
\hline $17 / 05 / 2015$ a $23 / 05 / 2015$ & 0,11 & 0,8 \\
\hline 24/05/2015 a 30/05/2015 & 0,94 & 6,6 \\
\hline
\end{tabular}

Tabela 15. Acompanhamento do estádio fenológico nas diferentes épocas plantadas ao longo do desenvolvimento da cultura.

\begin{tabular}{cccc}
\hline DA & DP & EP & EF \\
\hline $12 / 12 / 2014$ & $16 / 11 / 2014$ & $1^{\circ}$ & V2 \\
$12 / 12 / 2014$ & $28 / 11 / 2014$ & $2^{\circ}$ & V1 \\
$20 / 12 / 2014$ & $16 / 11 / 2014$ & $1^{\circ}$ & V5 \\
$20 / 12 / 2014$ & $28 / 11 / 2014$ & $2^{\circ}$ & V3 \\
$20 / 12 / 2014$ & $11 / 12 / 2014$ & $3^{\circ}$ & VC \\
$03 / 01 / 2015$ & $16 / 11 / 2014$ & $1^{\circ}$ & R1 \\
$03 / 01 / 2015$ & $28 / 11 / 2014$ & $2^{\circ}$ & V6 \\
$03 / 01 / 2015$ & $11 / 12 / 2014$ & $3^{\circ}$ & V3 \\
\hline
\end{tabular}




\begin{tabular}{|c|c|c|c|}
\hline $03 / 01 / 2015$ & $18 / 12 / 2014$ & $4^{\circ}$ & V2 \\
\hline 03/01/2015 & $02 / 01 / 2015$ & $5^{\circ}$ & VE \\
\hline $10 / 01 / 2015$ & $16 / 11 / 2014$ & $1^{\circ}$ & $\mathrm{R} 2$ \\
\hline $10 / 01 / 2015$ & $28 / 11 / 2014$ & $2^{\circ}$ & $\mathrm{R} 1$ \\
\hline $10 / 01 / 2015$ & $11 / 12 / 2014$ & $3^{\circ}$ & V4 \\
\hline $10 / 01 / 2015$ & $18 / 12 / 2014$ & $4^{\circ}$ & $\mathrm{V} 2$ \\
\hline $10 / 01 / 2015$ & $02 / 01 / 2015$ & $5^{\circ}$ & $\mathrm{VC}$ \\
\hline $14 / 01 / 2015$ & $16 / 11 / 2014$ & $1^{\circ}$ & $\mathrm{R} 3$ \\
\hline $14 / 01 / 2015$ & $28 / 11 / 2014$ & $2^{\circ}$ & $\mathrm{R} 2$ \\
\hline $14 / 01 / 2015$ & $11 / 12 / 2014$ & $3^{\circ}$ & V5 \\
\hline $14 / 01 / 2015$ & $18 / 12 / 2014$ & $4^{\circ}$ & V2 \\
\hline $14 / 01 / 2015$ & $02 / 01 / 2015$ & $5^{\circ}$ & V1 \\
\hline $14 / 01 / 2015$ & $06 / 01 / 2015$ & $6^{\circ}$ & VE \\
\hline $22 / 01 / 2015$ & $16 / 11 / 2014$ & $1^{\circ}$ & R5.1 \\
\hline $22 / 01 / 2015$ & $28 / 11 / 2014$ & $2^{\circ}$ & $\mathrm{R} 3$ \\
\hline $22 / 01 / 2015$ & $11 / 12 / 2014$ & $3^{\circ}$ & $\mathrm{R} 1$ \\
\hline $22 / 01 / 2015$ & $18 / 12 / 2014$ & $4^{\circ}$ & V6 \\
\hline $22 / 01 / 2015$ & $02 / 01 / 2015$ & $5^{\circ}$ & $\mathrm{V} 2$ \\
\hline $22 / 01 / 2015$ & $06 / 01 / 2015$ & $6^{\circ}$ & $\mathrm{V} 1$ \\
\hline $24 / 01 / 2015$ & $16 / 11 / 2014$ & $1^{\circ}$ & R5.2 \\
\hline $24 / 01 / 2015$ & $28 / 11 / 2014$ & $2^{\circ}$ & R5.1 \\
\hline $24 / 01 / 2015$ & $11 / 12 / 2014$ & $3^{\circ}$ & $\mathrm{R} 1$ \\
\hline $24 / 01 / 2015$ & $18 / 12 / 2014$ & $4^{\circ}$ & V7 \\
\hline $24 / 01 / 2015$ & $02 / 01 / 2015$ & $5^{\circ}$ & V3 \\
\hline $24 / 01 / 2015$ & 06/01/2015 & $6^{\circ}$ & $\mathrm{V} 1$ \\
\hline $31 / 01 / 2015$ & $16 / 11 / 2014$ & $1^{\circ}$ & R5.4 \\
\hline $31 / 01 / 2015$ & $28 / 11 / 2014$ & $2^{\circ}$ & R5.3 \\
\hline $31 / 01 / 2015$ & $11 / 12 / 2014$ & $3^{\circ}$ & $\mathrm{R} 2$ \\
\hline $31 / 01 / 2015$ & $18 / 12 / 2014$ & $4^{\circ}$ & $\mathrm{R} 1$ \\
\hline $31 / 01 / 2015$ & $02 / 01 / 2015$ & $5^{\circ}$ & V4 \\
\hline $31 / 01 / 2015$ & $06 / 01 / 2015$ & $6^{\circ}$ & $\mathrm{V} 2$ \\
\hline $04 / 02 / 2015$ & $16 / 11 / 2014$ & $1^{\circ}$ & R5.5 \\
\hline $04 / 02 / 2015$ & $28 / 11 / 2014$ & $2^{\circ}$ & R5.3 \\
\hline $04 / 02 / 2015$ & $11 / 12 / 2014$ & $3^{\circ}$ & $\mathrm{R} 4$ \\
\hline $04 / 02 / 2015$ & $18 / 12 / 2014$ & $4^{\circ}$ & $\mathrm{R} 1$ \\
\hline $04 / 02 / 2015$ & $02 / 01 / 2015$ & $5^{\circ}$ & V5 \\
\hline $04 / 02 / 2015$ & $06 / 01 / 2015$ & $6^{\circ}$ & V3 \\
\hline $11 / 02 / 2015$ & $16 / 11 / 2014$ & $1^{\circ}$ & R7.1 \\
\hline $11 / 02 / 2015$ & $28 / 11 / 2014$ & $2^{\circ}$ & R5.5 \\
\hline $11 / 02 / 2015$ & $11 / 12 / 2014$ & $3^{\circ}$ & R5.4 \\
\hline $11 / 02 / 2015$ & $18 / 12 / 2014$ & $4^{\circ}$ & $\mathrm{R} 4$ \\
\hline $11 / 02 / 2015$ & $02 / 01 / 2015$ & $5^{\circ}$ & $\mathrm{R} 1$ \\
\hline $11 / 02 / 2015$ & 06/01/2015 & $6^{\circ}$ & V6 \\
\hline $18 / 02 / 2015$ & $16 / 11 / 2014$ & $1^{\circ}$ & R7. 1 \\
\hline $18 / 02 / 2015$ & $28 / 11 / 2014$ & $2^{\circ}$ & R6 \\
\hline $18 / 02 / 2015$ & $11 / 12 / 2014$ & $3^{\circ}$ & R5.4 \\
\hline $18 / 02 / 2015$ & $18 / 12 / 2014$ & $4^{\circ}$ & $\mathrm{R} 4$ \\
\hline $18 / 02 / 2015$ & $02 / 01 / 2015$ & $5^{\circ}$ & $\mathrm{R} 2$ \\
\hline $18 / 02 / 2015$ & $06 / 01 / 2015$ & $6^{\circ}$ & V7 \\
\hline
\end{tabular}




\begin{tabular}{|c|c|c|c|}
\hline $23 / 02 / 2015$ & $16 / 11 / 2014$ & $1^{\circ}$ & R7.2 \\
\hline $23 / 02 / 2015$ & $28 / 11 / 2014$ & $2^{\circ}$ & R5.5 \\
\hline $23 / 02 / 2015$ & $11 / 12 / 2014$ & $3^{\circ}$ & R5.4 \\
\hline $23 / 02 / 2015$ & $18 / 12 / 2014$ & $4^{\circ}$ & R5.1 \\
\hline $23 / 02 / 2015$ & $02 / 01 / 2015$ & $5^{\circ}$ & $\mathrm{R} 3$ \\
\hline $23 / 02 / 2015$ & $06 / 01 / 2015$ & $6^{\circ}$ & $\mathrm{R} 1$ \\
\hline $28 / 02 / 2015$ & $16 / 11 / 2014$ & $1^{\circ}$ & R8.1 \\
\hline $28 / 02 / 2015$ & $28 / 11 / 2014$ & $2^{\circ}$ & R6 \\
\hline $28 / 02 / 2015$ & $11 / 12 / 2014$ & $3^{\circ}$ & R5.4 \\
\hline $28 / 02 / 2015$ & $18 / 12 / 2014$ & $4^{\circ}$ & R5.2 \\
\hline $28 / 02 / 2015$ & $02 / 01 / 2015$ & $5^{\circ}$ & R5.1 \\
\hline $28 / 02 / 2015$ & $06 / 01 / 2015$ & $6^{\circ}$ & $\mathrm{R} 1$ \\
\hline 09/03/2015 & $16 / 11 / 2014$ & $1^{\circ}$ & $\mathrm{R} 8.2$ \\
\hline 09/03/2015 & $28 / 11 / 2014$ & $2^{\circ}$ & R7.1 \\
\hline 09/03/2015 & $11 / 12 / 2014$ & $3^{\circ}$ & R5.5 \\
\hline 09/03/2015 & $18 / 12 / 2014$ & $4^{\circ}$ & R5.3 \\
\hline 09/03/2015 & $02 / 01 / 2015$ & $5^{\circ}$ & $\mathrm{R} 5.2$ \\
\hline 09/03/2015 & $06 / 01 / 2015$ & $6^{\circ}$ & $\mathrm{R} 4$ \\
\hline $14 / 03 / 2015$ & $16 / 11 / 2014$ & $1^{\circ}$ & R9 \\
\hline $14 / 03 / 2015$ & $28 / 11 / 2014$ & $2^{\circ}$ & $\mathrm{R} 7.3$ \\
\hline $14 / 03 / 2015$ & $11 / 12 / 2014$ & $3^{\circ}$ & R6 \\
\hline $14 / 03 / 2015$ & $18 / 12 / 2014$ & $4^{\circ}$ & R5.4 \\
\hline $14 / 03 / 2015$ & $02 / 01 / 2015$ & $5^{\circ}$ & R5.3 \\
\hline $14 / 03 / 2015$ & $06 / 01 / 2015$ & $6^{\circ}$ & R5.1 \\
\hline $21 / 03 / 2015$ & $16 / 11 / 2014$ & $1^{\circ}$ & R9 \\
\hline $21 / 03 / 2015$ & $28 / 11 / 2014$ & $2^{\circ}$ & $\mathrm{R} 8.1$ \\
\hline $21 / 03 / 2015$ & $11 / 12 / 2014$ & $3^{\circ}$ & R7.3 \\
\hline $21 / 03 / 2015$ & $18 / 12 / 2014$ & $4^{\circ}$ & R5.5 \\
\hline $21 / 03 / 2015$ & $02 / 01 / 2015$ & $5^{\circ}$ & R5.3 \\
\hline $21 / 03 / 2015$ & $06 / 01 / 2015$ & $6^{\circ}$ & $\mathrm{R} 5.2$ \\
\hline $28 / 03 / 2015$ & $16 / 11 / 2014$ & $1^{\circ}$ & R9 \\
\hline $28 / 03 / 2015$ & $28 / 11 / 2014$ & $2^{\circ}$ & $\mathrm{R} 8.2$ \\
\hline $28 / 03 / 2015$ & $11 / 12 / 2014$ & $3^{\circ}$ & $\mathrm{R} 8.1$ \\
\hline $28 / 03 / 2015$ & $18 / 12 / 2014$ & $4^{\circ}$ & R7. 1 \\
\hline $28 / 03 / 2015$ & $02 / 01 / 2015$ & $5^{\circ}$ & R6 \\
\hline $28 / 03 / 2015$ & $06 / 01 / 2015$ & $6^{\circ}$ & R5.5 \\
\hline $04 / 04 / 2015$ & $28 / 11 / 2014$ & $2^{\circ}$ & R9 \\
\hline $04 / 04 / 2015$ & $11 / 12 / 2014$ & $3^{\circ}$ & $\mathrm{R} 8.2$ \\
\hline $04 / 04 / 2015$ & $18 / 12 / 2014$ & $4^{\circ}$ & $\mathrm{R} 8.1$ \\
\hline $04 / 04 / 2015$ & $02 / 01 / 2015$ & $5^{\circ}$ & R7 \\
\hline $04 / 04 / 2015$ & 06/01/2015 & $6^{\circ}$ & R6 \\
\hline $11 / 04 / 2015$ & $11 / 12 / 2014$ & $3^{\circ}$ & R9 \\
\hline $11 / 04 / 2015$ & $18 / 12 / 2014$ & $4^{\circ}$ & $\mathrm{R} 8.2$ \\
\hline $11 / 04 / 2015$ & $02 / 01 / 2015$ & $5^{\circ}$ & $\mathrm{R} 8.1$ \\
\hline $11 / 04 / 2015$ & $06 / 01 / 2015$ & $6^{\circ}$ & R7 \\
\hline $18 / 04 / 2015$ & $18 / 12 / 2014$ & $4^{\circ}$ & R9 \\
\hline $18 / 04 / 2015$ & $02 / 01 / 2015$ & $5^{\circ}$ & $\mathrm{R} 8.2$ \\
\hline $18 / 04 / 2015$ & 06/01/2015 & $6^{\circ}$ & $\mathrm{R} 8.1$ \\
\hline $25 / 04 / 2015$ & $02 / 01 / 2015$ & $5^{\circ}$ & R9 \\
\hline
\end{tabular}




\begin{tabular}{cccc}
\hline 25/04/2015 & $06 / 01 / 2015$ & $6^{\circ}$ & R9 \\
\hline *Data da avaliação; **Data de plantio ; *** Época de plantio; ****Éstádio fenológico.
\end{tabular}

Data da avaliação; **Data de plantio ; *** Epoca de plantio; **** 